\title{
Ueber Iritis syphilitica mit Rücksicht auf ihr Verhalten zur allgemein luetischon Diathese.
}

\author{
Von \\ Dr. J. Widder, \\ Secundararzt des allgemeinen Krankeuhanses in Wien.
}

Vorliegende Arbeit ist das Resultat von Beobachtungen, die ich während meiner Thätigkeit an der Klinik für Augenheilkunde sowoll als an derjenigen für Syphilis durehzufähren Gelegenheit hatte. Das gesammelte ziemlich zahlreiche Material ging mir jedoch in Folge einer sehweren, sehr langwierigen Erkrankung zum grossen Theile verloren, und ich war daher genothigt, als Basis dieser Arbeit das Material der v. ArIt'schen Klinik allein zu benutzen. Es sei mir daher auch gestattet, meinem verehrten Lehrer Herrn Hofrath Professor v. Arlt für die Ueberlassung des reichen Materials seiner Klinik meinen besten Dank auszusprechen.

In Nachfolgendem will ich nun, bevor ich auf das eigentliche Thema des Näheren eingehe, in Kurzem den naturgemässen Verlauf der Syphilis sehildern, um so den einheitlichen Standpunkt festzostellen, von dem ans allein die richtige Beobachtung aller luetischen Manifestationen, daher auch diejenige der specifischen Angenerkrankungen, ausgehen kann. 
Die Syphilis ist eine der wenigen Krankheitsformen, deren Entwicklung wir in ihren Manifestationen sehrittweise zu beobachten vermögen. Die constitutionelle Syphilis baut sich, gestütat auf die feste Basis des gesetzten Grundsteines, nach einem gewissen Typus auf, sowohl betreffend die Lagerplätze, wohin sie das zum weiteren Aufbaue bestimmte Material bis zu seiner Verwerthbarkeit deponirt, wie auch nicht minder betreffend die Localisation und die Art der gesetzten Producte. Die Syphilis bietet in bestimmten Entwickelungsperioden Producte bestimmter Art. Die Verschiedenheit der luetischen Producte entspricht vollkommen dem gegenseitigen Verhältnisse zwischen abgelaufener Zeitdauer und der schon gethanen Arbeit. Diese Thatsache war es, die schon die frühesten Beobachter der Syphilis bewogen hat, die luetische Gesammterkrankung in einer durch sie selbst bestimmten Gesetzmässigkeit ablaufen zu lassen.

Joannes Fernelius*) (1486-1557) scheint der Erste gewesen zu sein, der im XV. Jahrhunderte schon, auf Grund seiner Beobachtungen die primären von den secundären Formen der Syphilis unterschied. Und seit dieser Zeit finden wir bei allen Autoren über Syphilis nur eigentlich mehr oder weniger Varianten dieser einmal festgestellten Beobachtung. Der Unterschied ist nur, dass, was früher einfach empirische Beobachtung gewesen, durch gelänterte klinische Frfahrung zur naturwissenschaftlichen Begründung der neueren Syphilislehre geworden ist. Erwähnen will ich nur noch, dass ein späterer Zeitgenosse Mrusa Brassavolus**) (1551) sich bereits für berechtigt hielt, fünf neue Arten der Syphilis aufzustellen. Dies lann hierort vielleicht insofern von Interesse sein, als derselbe als der Erste das Auge mit in den Bereich des luetischen Prozesses hineinbezieht, indem er die vierte Art der Syphilis als Occhiarola bezeichnet. Es wäre denn, dass

*) „De abditis rerum causis", lib. II und „De partium morbis et symptomatibus", lib. VI.

**) "De morbo gallico", liber Aphr. I, p. 658. 
wir auch dafür die Priorität dem grossen Psalmendichter zuerkennen wollten, welcher dem im Cap. 38, 30. Absehn. Gesagten ,non est pax in ossibus meis", die Worte folgen lasst. "gewichen ist das Licht von meinen Augen".

Jedoch nicht Historisches zu bieten ist mein Zweck, und ich will nun gleich auf den Begründer der bis in die neueste Zeit feststehenden Syphilislehre übergehen. Ricord*) war es, der in seinen Arbeiten den Grundstein zur gesammten netuen Syphilislehre niedergelegt hat. Ricord scheidet den gesammten luetischen Prozess in eine primäre, secundäre und tertiäre Periode. Dieser Fintheilung, als Ausdrucksweise des typischen Verlaufes der constitutionellen Syphilis, schliesst sich im Grossen und Ganzen die grösste Zahl der neueren Autoren an. [Sigmund**), Bärensprung***), Bäumlert), Lanceraux + ), Redert+十), theilweise auch Simon*t), Aus pitz*十)]. - So sagt Zeiss1: „Unter Syphilis verstehen wir eine, in Folge der Einwirkung eines eigenthümlichen thierischen Giftes hervorgerufene Blutvergiftung, durch welch letztere mannigfache Veränderungen in den verschiedensten Gewebssystemen des menschlichen Organismus in einer gewissen mebr oder weniger constanten Reihenfolge hervorgerufen werden. ${ }^{*} \dagger \dagger$ ) Und als würde er durch diese Definition den typischen Verlauf des luetischen Prozesses nicht genügend gekennzeichnet haben, spricht er sich noch folgendermassen aus: „Die Syphilis befällt nicht nur mit einer an Gesetzmässigkeit grenzenden Reihenfolge die einzelnen Gewebsysteme, sondern sie zeigt auch in den localen Krankheitserscheinungen, welche sie in Scene treten lässt, sowie in deren Metamorphosen, mit grösseren und geringeren Abweichungen eine gewisse Gesetzmässigkeit. $\dagger^{*}$ ) Und letzteres ist wohl das Wesentliche.

*) 1. c. 71, p. 198 und 1. c. 70, p. 318.

*⿻) 1. c. 100, p. 209.

****) 1. c. 11, p. 9.

†) 1. c. 13, p. 219.

†) 1. c. 55, p. 56 .

†十+) 1. c. 79, p. 219.

*) 1. c. 99, p. 448 .

*4t) 1. c. 6 , p. 374 .

*+f广) 1. c. 114, p. 1.

$\left.f^{*}\right)$ l. c. 114, p. 84. 
Auf Grund dieser Beobachtungen, welchen alle Autoren beistimmen, entstand nun die verschiedenartige, weil auf versehiedenartiger Basis beruhende Theilung des lnetischen Krankheitsprozesses. Es wird durch dieselben dem naturgemässen Abklingen der constitntionellen Syphilis nicht vorgegriffen. Im Gegentheil sie selbst weist klar genug den einzuschlagenden Weg, sie theilt sich selbst in Phasen, da der Prozess in vielen Fällen sich nicht in seiner Gesammtheit entrollt, sondern oft genug sich mit dem Fintreten der seiner Genesis zunächst stehenden Erscheinungen begnügt.

Ricord an der Spitze, wählte ein grosser Theil der Syphilodologen als Eintheilungsprincip die chronologische Reihenfolge der ergriffenen Gewebssysteme. Und wenn Ricord demselben eine physiologische und in Manchem auch anato mische Basis zufügt (Unterschied in der Uebertragbarkeit, in der Inoculation), so ist das empirische Criterium der Chronologie doch immerhin das vorwaltende. Es ist daher nur natürlich, dass diese Eintheilungsbasis einer geläuterten kliniseben und anatomischen Erfahrung nicht Stand halten konnte. Bei den neveren Autoren findet man demgemäss auch die Berücksichtigung der anatomisehen Verhältnisse mehr in den Vordergrund treten [Sigmund*), Bäumler**)]. Namentlich B ̈̈rensprung ***) betont geradezu das verschiedenartige anatomische Verhalten der constitutionellen Syphilis in der secundären und tertiären Periode. Er weist nach, dass, während die secundäre Lues wesentlich Hyperämien und einfache Exsudationen setze, die tertiäre dagegen überall Tuberkel (gummata) producire. Es ist dies schon eine wesentliche Modification des Ricord'schen Eintheilungsprincipes. Zeissl kann jedoch als der Erste betrachtet werden, der nur die Producte des luetischen Gesammtprocesses als Basis seiner Fintheilung benutzt und demgemäss die durch die Anatomie gewonnenen Resultate mit der klinischen Erfahrung in Einklang zu bringen sich bestrebt. Diese Eintheilung schliesst sich auch am innigsten an den naturgemässen Verlauf der constitutionellen Syphilis an. Zeissl findet die Berechtigung fûr seine Eintheilang in $z$ wei grosse Gruppen darin, dass die

*) 1. c. 100, p. 209 .

**) 1. c. 13, p. 25 .

***) 1. c. 12 VI. B., p. 56 und VII. B., p. 173. 
Krankheitsformen der späteren Periode ganz anderer Natur sind, als die kurz nach der Infection auftretenden. Er scheidet daher den Verlauf der Syphilis in zwei Phasen: 1) Stadium der nässenden Papeln (condylomatöses Stadium), 2) Stadium der gummösen Neubildungen (gummöses Stadium)*).

Was immer aber als Eintheilungsprincip der Kliniker gelte, Alle ohne Ausnahme stimmen darin überein, dass der Frühperiode der Syphilis leichtere Formen als luetische Manifestationserscheinungen entsprechen (secundäre), während die schwereren (gummösen) Neubildungen (tertiäre) erst nachkommen. Bei Production gummöser Neubildungen liabe die Lues als solche, wie Zeissl richtig bemerkt, ihren "Culminationspunkt" erreicht, sie bilden das specifische, nur der Lues eigene Endproduct. Das Gumma macht gewissermassen den Schlussstein in der Reihenfolge anderweitiger consecutiv Iuetischer Erscheinungen. Und da das Knotensyphilid unter allen Syphiliden am spätesten erscheint und immer erst in einer der Infection weit entrückten Phase des luetisehen Processes zu finden ist, so ist dasselbe in der Zeit das alleinige luetische Product. „Das Gumma kommt nicht in Verbindung mit den papulösen und pustalösen Formen der frühen Periode der Syphilis vor", sagt Sigmund $\mathrm{d}^{* *}$ ) and behauptet, nie einen Fall von Gumma in den ersten 6 Monaten der constitutionellen Erkrankung gesehen za haben. Viel bestimmter spricht sich noch Zeissl $\left.{ }^{* * *}\right)$ aus, der geradezu betont, dass luetische Frühformen und Gumma sich zeitlich gegenseitig ausschliessen. „Da das Knotensyphilid das Ergebniss einer späteren Phase der syphilitischen Lrkrankungsform ist, so kann dasselbe mit keiner derjenigen Erscheinungen gemeinsam auftreten, welche eben der frühen Phase der Syphilis eigen sind (das heisst, man findet bei Knotensyphilid keine anderen Formen der frühen Periode, höchstens einzelne Ecthymata oder Rupiengeschwüre). Während mit den. der frühen Phasen in den meisten Fällen an den bereits bekannten Stellen nässende $P$ a peln vorkommen, kann man von einem mit dem Knotensyphilide behafteten Kranken a priori mit voller Gewissheit behaupten, dass er nicht nur zur Zeit keine nässenden Papeln besitzt, sondern solange keine besitzen wird,

*) 1. c. 114, p. 85 .

**) 1. c. 100. p. 236 ,

****) 1. c. 114, p. 177 u. 178. 
als er unter dem tinflusse der gegenwärtigen syphilitischen Bluterkrankung steht. Es zeigt diese Thatsache ganz klar, dass diese Prodnete ganz verschiedener Natur sind und dass die auf diese Basis gestützte Eintheilung des luetischen Gesammtprocesses eine wohl berechtigte ist. Das ist nun der klinische Standpunkt.

Welcher Art sind die anatomischen Thatsachen? Wir müssen zugestehen, dass die anatomischen Ergebnisse die durch die klinische Beobachtung gegründete Eintheilung nur in beschränktem Masse unterstützen. Virebow ${ }^{*}$ ) als der Erste, welcher die sypalititischen Producte einer gründlichen anatomischen Untersuchung unterzogen hat, behauptet, ,die anatomische Untersuchung löst diesen Unterschied gänzlich auf"; Producte dos luetischen Processes, mögen dieselben welcher klinischen Phase immer angehören, können vom anatomischen Standpunkte nicht unterschizden werden. Secundäre (dem condym lomatösen Stadium angehörende) und tertiäre (dem gummösen Stadium zukommende) Producte, ja selbst der initiale Primär affect, sind anatomisch vollkommen übereinstimmend. Dieses ist Thatsache, trotzdem die klinische Beobachtung nachweist, dass sich nicht nur die zwei Hauptmanifestationen der luetitischen Crase - Sclerose und Gumma - zeitlich ausschliessen, sondern dass dies anch für secundür luetische und gummöse Producte gilt. Dieses Factum wird anch nicht durch die Virchow'sche**) Angabe geändert, dass es zur Production gummöser Producte einer gewissen "Energie" und "Grösse" der specifischen Substanz bedarf, welche dieselbe sicherlich. erst nach Ablauf einer gewissen Zeitdauer zu erlangen vermag (Zeissl's Culminationspunkt).

Ob die Anatomie uberhaupt vollkommen berechtigt sei, bei vollkommener Unmöglichkeit zwei Endpole eines Krankheitsprocesses, - Initialsclerose und Gumma - von einander zu scheiden, eine begründete klinische Thatsache so gänzlich umzustossen, will ich hier nicht entscheiden. Ebensowenig, $o b$ es der Anatomie angemessen, der Klinik die Berechtigung zur Scheidung dessen zu entziehen, was sich naturgemäss differenzirt, zur Scheidung secundär und tertiär luetischer Producte. Nor so viel möchte ich hier bemerken, dass die

*) 1. c. 109, p. 327 .

**) 1. c. 110, p. 77, I. B. 
Anatomie heute noch ausser Stande, Localstörungen entzündlicher Natur, auch solche, welche aetiologisch sowohl als klinisch am weitesten von einander stehen, zu scheiden (Virchow*). Es darf daher nicht auffallen, wenn Producte der Syphilis, die ihrer Aetiologie und ih rem Wesen nach so nahe stehen, durch die Anatomie nicht differenzirt werden können.

Die anatomischen Ergebnisse scheinen aber auch bei den Anatomen selbst nur Unzufriedenheit erweckt zu haben, welche sich der Einsicht nicht verschliessen konnten, dass diese Resultate in ihrer Totalität nicht durchführbar seien. So betont Rindfleisch**), dass in den frähen Phasen der Allgemeinerkrankung mehr die oberflächlichen Organe, in den späteren die tieferliegenden ergriffen werden. Diese Ansicht entspricht sogar der Ric ord 'schen Eintheilung. Eine so strenge Scheidung in den Krankheitserscheinungen besteht aber de facto nicht. Vir chow**is ) selbst muss zugestehen, dass der luetischeProcess an allen genauer bekannten Localitäten loichtere und schwerere Veränderungen hervorbringt. Er scheidet demgemäss vom anatomischen Standpunkte zwei Reihen von Producten: eine die sich mehr den gewöhnlichen hyperplastischen entzündlichen Formen anschliesst, eive zweite Reihe, welche mehr Analogien mit specifischen Irritationen aufweist. Die ersteren entsprechen den einfach entzündlichen, irritativen oder formativen Veränderungen, die letzteren, schwereren dagegen weisen sehon den Charakter heterogener, mehr oder weniger specifischer Productivität auf. Virchow giebt fermer za, dass die leichteren und oberflächlichen Formen der frühen, die schwereren dagegen dor späteren Phase der Lnes angehören. Nur will er vom anatomischen Standpunkte diese Scheidung der luetischen Producte in der Zeit nicht auf das Gesammtleiden ausgedehnt wissen, vielmehr auf die Localerkrankung beschränken.

Um das Gesagte zusammenzufassen, sind also im Laufe der constitutionellen Syphilis zweierlei Entwicklungsreihen zu unterscheiden: die einfach hyperplastischen Formen, welehe die leichteren Reizungszustände kennzeichnen, und die

\footnotetext{
*) 1. c. 110 . IT. B., p. 390 .

**) L. c. 81, p. 82 .

***) 1. c. 109, p. 320 u. 328 .
} 
schwereren, als welche Virohow die der Heteroplasio sich annähernden GummawGeschwälste betrachtet. Im Allgemeinen gehören die leichteren den früheren Zeiten, die schwereren den späteren Zeiten der Localerkrankung an und in diesem Sinne können aus der "Aneinanderreihung der Symptome" frühe und späte Formen unterschieden werden. Die vin Virchow aufgestellite anatomische Eintheilung der sypbilitisehen Localprocesse enthalt demnach drei grosse Reihen: 1. Die einfachen irritativen (hyperplastischen), 2. die gummösen (specifisch heteroplastischen), 3. die amyloiden Veränderungen, welch letztere der syphilitischen Cachexie zukommen. Diese anatomische Eintheilung ist mit der rom Zeissl auf Grund klinischer Beobachtung durchgeführten Scheidung der Lues vollkommen übereinstimmend. Das Stadium der nässenden Papoln (condylomatöses Stadium) entspricht den irritativen (byperplastischen), das Stadium dex gummöseu Neubildungen, den gummösen (specifisch heteroplastischen) Veränderungen Virchow's. Ich erkenne daher diese Eintheilung des luetischen Processes als die allein richtige und naturgemässe an. Dieselbe bildet die Basis aller spăter zu erwähnenden Beobachtungen.

Virchow*) hat noch einen Beweisgrund angeführt, welcher nachweisen sollte, dass es ungerechtfertigt sei, secundäre und tertiäre Producte von einander zu scheiden. Er meint, dass, falls eine so strenge Scheidung der beiden Phasen der Syphilis schon durch die Natur des Krankheitsprocesses und nictt durch Zufalle bedingt wäre, man das Recht hätte zu erwarten, dass demgemäss auch die therapeutischen Angriffs. punkto röllig rerschieden sein miissten. Dieser Ansicht mochte ich zunächst entgegenstellen, dass die Therapie behufs Entseheidung des Wesens der Krankheitsprocesse überhaupt nie herangezogen werden kann. Welcher Kliniker wollte oder könnte mit Recht behaupten, dass eine verschiedenartige Therapie eine unbedingte Verschiedenheit des Krankheitsprocesses erfordert, die Gleichheit der Therapie das Analoge der Erkrankungsform involvirt. Uebrigens möchte ich der Thatsache Erwähnung thun, dass der obige therapeutische Standpunkt, falls überhaupt irgendwo, bei der Lues gerade einigermassen Verwendung finden $\mathrm{kam}$. Es lehrt die vorurtheils-

*) 1. c. 109, p. 218. 
freie Beobachtung, dass während secundär luetische Producte (im Sinne ZeissI's) auf Hg auffallend prompt und zwar in günstigem Sinne reagiren, es andererseits nicht selten ist, dass dieses Resultat bei tertiär luetischen Producten entweder gänzlich ausbleibt, oder man geradeza einen Misserfolg constatiren kann. Dagegen haben Jodpräparate gerade bei tertiär luetisehen Producten ein auffallend günstiges Resultat.

Die Versehiedenheit der syphilitisehen Prodncte ist ihrem ganzen Wesen nach eine so eminente, dass manche Autoren den gesammten luetisehen Process sogar in zwei verschiedenartige Krankheitsformen theilen. So rechnet Bäumlex*) nur die secundären Producte zur eigentlichen constitutionellen Erkrankung, während er die tertiären Producte als Resultat einer Nachkrankheit betrachtet. In der Tertiärperiode sei bereits das syphilitische Virus eliminirt, im Gegensatze zur Frühphase, wo das Blut Träger eines specifischen Virus sei. Das Individuum wäre daher zur Zeit der Nachkrankheit eigentlich nicht mehr constitutionell syphilitisch erkrankt. Ich halte dafür, dass er diesfalls etwas zu weit gegangen ist.

Es wäre durchaus falsch, wenn mir Jemand die Absicht unterschieben wollte, dass ich im Verlaufe der constitutionellen Syphilis seltene Ausnahmsfälle ansschliesse. Dieselben können nur nicht hinreichend gewichtige Gegengründe gegen das allgemein Geltende abgeben. Eine nicht geringe Zahl dieser Ausnahmsfälle ist geradezu Kunstproduct. „Oft ist die schönste Unordnung das Werk der Kunst", sagt Ricord. Bei der Syphilis ist die Therapie in nicht seltenen Fällen Urheberin dessen, dass das naturgemässe Abklingen der constitutionellen Erkrankung gestört, ihr Verlanf unnatürlich wird. Es ist dies eine Thatsache der Erfabrung, die Zeissl sowie Simon**) betont. Namentlich allzufrühe Quecksilberbehandlung hat sicher einen Einfluss, und zwar keinen günstigen auf den normalen und naturgemässen Verlauf der Syphilis.

Nach dieser Durchstreifung fremden Gebietes, will ich hiermit auf das eigentliche Thema dieser Arbeit ubergehen.

\footnotetext{
*) 1. c. 13, p. 58 .

) 1. c. 99, p. 449 .
} 
Welches ist das Verbaltniss zwischen luetischen Erkrankungsformen der Iris und der allgemein luetischen Diathese?

Bei Beantwortung dieser Frage will ich, um innerhalb der mir vorgesteckten Grenze zu bleiben, die Iritis specifica im Allgemeinen, die Iritis gummosa des Naheren in's Auge fassen. Beror ich dies jedoch thue, sei es mir gestattet, einzelne allgemeine Bemerkungen zu erörtern, betreffs der Art und Weise wie ich meine Beobachtungen bei den auf luetischer Grundlage erkrankten Augen durchgeführt habe.

Diespecifischen Erkrankungs formen desAuges sind Lokalmanifestationen der constitutionellen Syphilis. Sie sind es ebenso wie die anderweitigen, an verschiedenen Theilen sich lokalisirenden luetischen Producte. Die Beobachtung derselben kann daher nur dann eine richtige sein, wenn sie stets in innigem Zusammenhange mit der Beobachtung des Allgemeinleidens durchgeführt wird. Ich glaube nicht zu irren, dass die Ausserachtlassung dieses wesentlichen Momentes mit Ursache der vorhandenen Unklarheit nnd Unsicherheit ist, welche bei Beurtheilung der specifischen Augenerkrankungen noch vorherrscht. Denn, während Syphilidologen ungewohnt sind, die Frkrankungen des Auges gehörig zu witrdigen, herrscht anderseits bei Oculisten die Geneigtheit vor, die specifische Irritation des Auges zu einer gewissen Isolirtheit zu erheben. Das Localproduct erlangt so im Laufe der Beobachtung eine selbstständige Rolle, wogegen dieselbe vielmehr als Theil eines Ganzen der allgemein constitutionellen Erkrankung untergeordnet werden müsste.

Die Iris unterliegt, ganz so wie die meisten Gewebe, der durch das specifische Virus bedingten Irritation. So viel scheint gewiss zu sein, dass eine syphilitische Iritis primär entstehen kann, in dem Sinne, dass es zu ihrer Entstehung keiner besonderen Gelegenheitsursache bedarf, 
wenigstens keiner solchen, die eine verschiedenartige wäre von derjenigen, die bei Producirung anderweitiger luetischer Producte obwaltet. Ich glaube daher auch, dass die von Leber*) ausgesprochene Ansicht, dass die Iritis syphilitica bedingt sei durch etwaige von syphilitischen virushaltigen Partikelchen entstandene Gerinnsel, - daher eine Gelegenheitsursache - eine zwar geistreiche aber durch nichts berechtigte und gestutzte Hypothese sei.**) Wenn daher

*) 1. c. 53, p. 125 .

*) Zur Beseitigung missverständlicher Auffassung meiner Ansichten bin ich genöthigt, hier einige Bemerkungen beizufügen. Ich sage am angeführten Ort, die Entstehungsweise der localen Affecte des Auges bei secundärer Syphilitis sei uns zwar noch unbekannt, nach der Art und Weise ihres Auftretens sei aber unzweifelhaft anzunehmen, dass die entzündungserregende Ursache dem Auge durch den Blutstrom zugeführt werde, womit wohl Jedermann einverstanden sein wird, welche Vorstellung er auch über die Natur des Virus haben mag. Ich lege nun das Hauptgewicht auf die bekannte und auch von Herm Dr. Widder wiederum bestätigte Erfahrung, dass die syphilitische Iritis sehr oft einseitig auftritt und fahre fort: "Wie sollten wir uns das Entstehen einer einseitigen Iritis syphilitica anders erklären kömnen als dureh die Annahme, dass virushaltige Partikelchen, kleine Gerinnsel etc. in den Gefüssen einer Iris liegen bleiben, während in das andere Ange zufällig davon Nichts hineingelangt oder nur so kleine Stückehen, dass sie die Oapillaren ohne Anstand passiren können?"

In der Regel ist doch von einer Verletzung oder sonstigen äusseren Schädlichkeit, die nur auf ein Auge einwirkte, keine Rede; die Einseitigkeit des Anftretens schien mir deshalb mit der Annahme eines in Blute gelösten, oder nur als einzelne feinste Körnehen darin enthaltenen Virus unvereinbar, weil dasselbe dann anf beide Augen gleichmässig wirken müsste. Dies führte mich zu der Annahme, dass etwas gröbere körperliche Gebilde im Spiele sein möehten, imamerhin von mikroskopischen Dimensionen, die aber die Capillaren nicht anstandslos passiren könnten, etwa kleine Colonien der specifischen Mikrobien, oder kleine zarte Gerinnsel, welche solche parasitäre Elemente einschlössen. Die Entstehung von Blatgerinnungen in der Umgebung fremder Körper ist zu bekannt und besonders bei Spaltpilzen im Inneren der Blutgefässe so häufig nachgewiesen, dass 
in diesem Sinne die Möglichkeit einer primären syphilitisehen Iritis zugegeben werden muss, so halte ich es doch nicht für unnöthig, auch auf Momente zu verweisen, denen bei der Erzengung einer syphilitischen Iritis wohl eine wichtige Rolle zugesprochen werden muss. Ich meine damit äussere Veranlassungen der verschiedensten Art. Es können dies solche sein, die sonst in einem gesunden $0 \mathrm{r}$ ganismus bloss leichte Reizerscheinungen seitens der Iris hervorrufen, bei luetiseher Diathese dagegen den Anstoss abgeben können, zur Entwicklung gestejgerter Irritation, zur Entzündung der Lris. Wir können es aber auch dann poch mit einer auf luetischer Basis beruhenden Entzündung dieser Membran zu thun haben. Diese Ursache kann vielleicht eine lebhaftere Zufuhr und mit derselben eine locale Anhäufung des in dem Zugefuhrten enthaltenen specifischen Virus bewerkstelligen, oder aber die bereits vorgefundenen specifischen Elemente zu emenerter Lebensthätigkeit anfachen.

Aeussere Gelegenheitsursachen können übrigens auch an anderen Organen auf die Entwicklung Inetiseher Producte begünstigend einwirken. Es ist eine den meisten Beobachtern der Syphilis bekannte Thatsache, dass Secundärproducte der Lues (z. B. papulöse Efflorescenzen) sich in grösserer Anzahl an Stellen entwickeln, welche einer durch. Gelegenheitsursachen bedingten Hyperämie oder besser gesagt Irritation ausgesetzt sind. Man beobachtet ferner, dass, während es an den äbrigen Körpertheilen bloss zur

man hier wohl kaum von einer "geistreichen" Hypothese sprechen kann.

Auch an anderen Organen, wenn, wie gewohnlich bei Iritis, eine äussere Gelegenheitsursache fehlt, werden wir uns den Her" gang in annlicher Weise vorzustellen haben. Wo dagegen die Mitwirkung äasserer Schädlichkeiten angenommen werden kan, erkenne icl deren Winfuss auf die Entstehung und Form rer Localisationen vollkommen an.

Th. Leber. 
Entwicklung einer einfachen Roseola oder eines Erythema maculosum kömmt, man an den irritirten Stellen die einzigen mächtigeren luetischen Producte, papulöse Efflorescenzen findet. Diese Stellen sind auch oft genng die Prädilectionsstellen für recidivi ende papulöse Producte, bei Verschonung aller anderen Theile der äusseren Bedeckung. Durch solche äussern Sebädlichkeiten werden auch Mund- und Rachenschleimhaut, Anal- und Scrotalfalten Lieblingsstellen für luetische Producte, wie sich diese Orte dadurch anch zur Hervorbringung der mächtigsten secundär-luetischen Producte am besten eignen. Es hängt die eben berührte Frage mit der allgemeinen Vulnerabilität luetischer Individuen zusammen. Wenn nun diese anderweitigen Prodncte der constitutionellen Syphilis ihre Specifität beibehalten, so glaube ich auch mit Recht, dass eine auf demselben, etwa mittelbaren Wege entstandene Entzündung der Iris den specifischen Charakter beibehalten kann. Es entspricht jedoch den Thatsachen, wenn ich das eben Bemerkte nur auf jene Entwieklungsphase der Syphilis beschränkt wissen mbehte, wo in Folge erhöhter Erregbarkeit des Organismus auf geringfugige Reize alle Gewebe Geneigtheit zu aktiven Hyperämien aufweisen. Dieses nicht der Norm entsprechende gegenseitige Verhältniss zwischen Grösse der Ursache und der dadurch gesetzten Höhe der Reizerscheinungen charakterisirt hauptsächlich die Frühphase, das condylomatöse Stadium.

Die hierdurch angeregte Frage ist, auf welche Entwickelungsphase der constitutionellen Syphilis die grösste Zahl der Iritiden überhaupt entfalle. Wann kann man sich auf Grund kliniseher Beobachtungen fur berechtigt halten, eine Entzündung der Iris als eine von der Allgemeinerkrankung unmittelbar abhängige Theilerscheinung zu bezeichnen? Die Erfahrung lehrt, dass neben der Syphilis alle anderweitigen Erkrankungsformen der verschiedensten Organe als selbstständige Processe mitbestehen und ab- 
laufen können. Wir müssen bei der Betrachtung des Auges and speciell der Entzindung der Regenbogenhaut bei Syphilitischen den Grundsatz festhalten, dass auch bei diesen eine genuine Iritis nicht ausgeschlossen sei. Denjenigen Ursachen, die bei einem sonst normalen Individuum eine Iritis bedingen, muss es unbenommen bleiben, auch bei vorhandener Syphilis eine idiopathische Iritis hervorrufen zu können. Das ist es, was den klinischen Beobachter stets zur grössten Vorsicht mahnen muss, denn bis heute noch besteht die Richtigkeit der Stellwag'schen *) Ansicht „es giebt kein locales Symptom und keine Combination von localen Krankheitserscheinungen, welche eine gegebene Iritis zur syphilitischen stempeln liesse." Man darf daher die specifische Erkrankung der Iris immer nur mit strenger Rücksichtnahme auf die Allgemeinerkrankung und ihre anderweitigen lokalen Producte beobachten und beurtheilen, denn dieselbe ,kann ihre Analogie auch in einer genuinen Iritis finden."**) Nach dem heutigen Stande der Frage bleibt für die Specifität der Iris nur die Beobachtung massgebend, wie sich auch Arlt ausspricht, dass eben das haufige gleichzeitige Vorkommen mit anderweitigen luetischen Producten es wahrseheinlich macht, dass die Iritis ebenso gut wie alle anderen, namentlich secundär luetischen Manifestationen, Ausdruck des Allgemeinleidens sei.

Welche Entwicklungsphase der Syphilis bietet uns nun die grösste Wahrscheinlichkeit für die Specifität der vorhandenen Iritis? Während die älteren Autoren die syphilitische Iritis als ein Symptom der tertiären Lues betrachteten ( $v$. Ammon, fruher anch Ricord), so bezeichnen jetzt mit Recht sowohl Syphilodologen als Ophthalmologen die einfach specifische Iritis als die häufigste Begleit-

*) 1. c. 86, p. 283 .

*) I. c. 85 , II, B., p. $26 \vec{i}$. 
erscheinung secundär syphilitischer Processe. Man findet nur insofern Meinungsverschiedenheit, als Manche das häufige (Carmichael sogar das fast ausschliessliche) gleichzeitige Auftreten mit secundär luetischen Producten betonen, andere dieselbe zeitlich etwas später verlegen, meistens während der Involution obiger Producte oder aber unmittelbar nach bereits erfolgter Involution.

In nenerer Zeit gelangten doch auch Fälle zur Beobachtung, wo die Iritis den Reigen secundär syphilitischer Producte eroffnete. Wir finden darüber Angaben von Stellwag*), Mauthner $\left.{ }^{* *}\right), \quad$ Seitz-Zehender $\left.{ }^{* * *}\right)$, Arlt $)$, Boek $\dagger$ ). Ich selbst habe 3 Fälle zu beobachten Gelegenheit gehabt, wo bei Vorhandensein einer unzweifelhaften Initialsclerose, bei sonst günstigen äusseren Verhältnissen, plötzlich Iritis auftrat. Da mit Ausnahme des vorhandenen Primäraffectes kein anderweitiges ätiologisches Moment aufgefunden werden konnte, so hielt ich mich für berechtigt, die Iritis als eine specifische zu bezeichnen. In dieser Ansicht wurde ich noch bestärkt durch das nach kurzer Zeit erfolgende Auftreten eines theils maculo-papulösen, theils papulösen Syphilides. Dafür sprach auch der auffallend rasche günstige Einfluss einer nur geringen Zahl von Quecksilberinunctionen; 8 Inunct. à $2 \mathrm{Grm}$. bewirkten eine rapide Abnahme aller der Iritis zukommenden Krankheitserscheinungen. Eine solch' prompte Besserung auf verhältnissmässig geringe $\mathrm{Hg}$-Quantitäten wird fast ausnahmslos nur bei frischen specifischen und namentlich auch secundär-luetischen Producten beobachtet. In keinem der drei Fälle betrug die Zwischenzeit zwischen Auftreten der Iritis und den darauf folgenden Syphiliden mebr als

*) I. e. 86, p. 282

$*$ ) l. c. 59 , p. 270 .

${ }^{* * *}$ ) l. c. 87, p. 267.

† 1. c. 2, p. 53 .

t) I. e. 10 .

v. Oraefe's Archiv für Ophthalmologie, XXVII. 2. 
12 Tage. In dem ersten Falle waren es 4 Tage, im zweiten 12 Tage, im dritten 9 Tage.

Was nun die Beweismittel dafür anbelangt, dass die Iritis specifica thatsächlich ein Frühsymptom der constitutionellen Syphilis sei, so verweise ich auf eine Anzahl an der v. Arlt'schen Klinik zur Beobachtung gelangter Fälle, welche ich am Schlusse der Arbeit tabellarisch zusammengestellt habe. Die Zeit innerhalb welcher diese Falle zur Aufnahme gelangten, beträgt etwas mehr als 6 Jahre, das heisst ron 1874-1880, bei einer Gesammtzahl der klinischen Patienten von nahezu 5000. (Vide Tabelle I.)

Die Gesammtzahl der Falle, welche in den klinisehen Protokollen mit der Diagnose Iritis syphilitica (ohne Knoten) figurirten, war 59. Es waren daher ausser den in Tabelle I mitgetheilten 49 Fällen noch 10 andere mit der Diagnose Iritis specifica geführt. Ich habe diese 10 Fälle in die Tabelle aus folgenden Gründen nicht aufgenommen; zunächst waren darunter 3 Fälle, wo jede weiteren Angaben über etwa vorhandene oder abgelaufene luetische Erscheinungen ermangelten (Fall 50, 51, 52); $4 \mathrm{Mal}$ (Fall 53, 54, $55,56)$ gelangten die Patienten mit recidivirender Iritis zur Beobachtung, daher dieselben für das primäre Entstehen der syphilitischen Iritis keine Anhaltspunkte boten. Bei 2 Fallen (Fall 57, 58) war beim Eintritte nichts von Lues nachweisbar und nur auf Grund der eigenen Angaben der Patienten, dass dieselben ror 6-8 Jahren an einem nicht näher belannten Ausschlage gelitten, wurde die Diagnose auf Iritis specifica gestellt. Den einen noch erübrigenden Fall (59) will ich seines hohen Interesses halber hier in extenso mittheilen.

Patientin, 35 Jahre alt, giebt an, seit 10 Jahren verheirathet $z u$ sein und zwei lebende gesunde Kinder geboren zu haben. Sie soll sich vor acht Jahren von ihrem Manne eine Infection zugezogen haben, über deren weiteren Verlauf sie ausser Stande war, Bestimmtes anzugeben. Seit etwa 
7-8 Monaten bemerkte sie ohne weitere erhebliche Beschwerden eine langsame Abnahme ihres Sehvermögens, und zwar beiderseits. Seit 3-4 Monaten tritt zeitweise eine etwa 4-5 Tage andanernde Rothung beider Augen auf, mit Druck und Schmerzgefühl sowie Abnahme des Sehvermögens. Patientin ist kräftig gebaut, jetzt stark herabgekommen. Sie weist mit Ausnahme geringer Schwellung einzelner Nackendrüsen keine weiteren der Lues zukommenden Veränderungen auf. Beide Augen zeigen in charakteristischer Weise die Zeichen einer seit längerer Zeit bestehenden chronischen Iritis. Spur von Ciliarinjection, die Conjunctiva bulbi zeigt einen Stich ins schmutzig gelbe, Irides atrophisch, verfärbt, durch zahlreiche feine hintere Synechien an die Capsel adhärent. Rechts ist eine feine Membran in der Pupille, und der Glaskörper seheint etwas diffus getrübt. Soweit es bei den durch die Medien gegebenen dioptrischen Hindernissen möglich ist, lässt sich am Fundus beiderseits nichts Abnormes constatiren.

R. A. $\mathrm{S} \frac{6}{60}$ I. A. $\mathrm{S} \frac{6}{36}$ ? Gläser bessern nicht. Bei der Patientin wurde ihrer Angabe gemäss Iritis specifica diagnosticirt und die entsprechende Therapie durchgeführt. Es zeigte sich jedoch auch nach 30 Inunctionen à $4 \mathrm{Grm}$. absolut keine Besserung und sogar die zeitweiligen Exacerbationen in Form stärkerer Ciliarinjection traten wie früher ein. $\mathrm{Da}$ unter solehen Verhältnissen eine vollständige Seelusio pupillae zu befürchten stand, entschloss sich $v$. Arlt zur Iridectomie rechterseits, - bei weiterer Darreichung von. Jodkalium. Es zeigte sich nun, dass das rechte iridectomirte Auge sich zusehends erbolte, links jedoch trotz einer dureh 3-4 Wochen durchgefuhrten Jodkalium-Behandlung der Zustand sich gleich blieb. Es wurde daher auch links iridectomirt. Das Resultat war, dass während der als Iritis specifica bezeichnete Krankbeitsprocess weder auf $\mathrm{Hg}$. noch Jod irgend welche Veränderung zeigte, die Iridectomie beiderseits eine constante und wesentliche Besserung bewirkte. Das Endresultat war ganz so wie dies häufig nach Iridectomien bei chronischen Iritiden überhaupt beobachtet wird. R. A. $\mathrm{s} \frac{6}{24}$ L. A. $\mathrm{s} \frac{6}{18}$.

Woher konnte man das Recht ableiten, diesen Krankheitsprocess als einen specifisch luetischen zu kennzeichnen? 
Wenn ich die in Tabelle I enthaltenen Fälle genauer analysire, so ergiebt sich Folgendes: Bei 38 von den daselbst enthaltenen 49 Fällen lagen bestimmte Angaben über gleichzeitig vorhandene anderweitige luetische Producte vor; bei 11 mangelten dieselben und es waren nur Angaben über die Zeit des Primäraffectes gemacht worden.

Wo Angaben über Inetische Producte waren, gehörten dieselben dem condylomat. Stadium . in 37 Fällen

Wo Angaben über luetische Producte waren, gehörten dieselben dem gummösen Stadium . . . . . . . . . , . in

Wo nur Zeitangabe über den Primüraffect, entstand die Iritis 5 Woohen bis 6 Monate post infect.

Wo nur Zeitangabe über den Primäraffect, entstand die Iris im 8. Monate post infect.

Die Iritis fällt daher fast ausschliesslich in die Frühphase der Syphilis und ist ein Product des condylomatösen Stadiums. Wir haben also nur dann das Recht, eine gegebene Tritis als eine direct von der Allgemeinerkrankung unmittelbar abhängige, eigentlich specifische zu bezeichnen, wenn das condylomatose Stadium der constitutionellen Syphilis objectiv nachweisbar ist.

Ganz anders verhält es sich mit denjenigen Iritiden, die sich eventuell der Spätperiode, dem gummösen Stadium der Syphilis zugesellen. Unter den sämmtlichen der von Arlt'schen Klinik entnommenen 59 Fullen ron Iritis syphilitica habe ich überhaupt nur 4 , wo angenommen werden könnte, dass die Syphilis sich im gummösen Stadium befunden habe (Fall 57, 58, 59 und 19). Von diesen wären aber 3 (Fanl 57, 58, 59) eigentlich wegzulassen, da die Diagnose syphilitischer Iritis auf zu vager Basis gestellt war. Namentlich "was Fall 59 betrifft, so ist bei diesem 
Alles, was als wesentlicher Entscheidungsgrund in Betracht gezogen werden darf, sicher zu. Ungunsten der Specifität ausgefallen. Denn nichts charakterisirt mehr die Iritiden als wahre specifische Krankheitsprocesse, mit Ausnabme des häufigen Zusammentreffens mit anderen secundär luetischen Producten, als die auffallend rasche günstige Wirkung antiluetischer Mittel auf verhältnissmässig schon geringe Quantitäten. Ich kann daher diesen Fall aus diesen Gründen, schon wie auch seinem ganzen klinischen Verhalten nach, nur als eine chronische Form der Iritis anerkennen. Es bleibt somit nur ein Fall (Fall 19) übrig, wo Iritis im gummösen Stadium auftrat. Dieser eine Fall nun, ebenso wenn ich noch die zwei anderen (Fall 57, 58) Fälle von Iritis mit berücksichtige, beweisen, dass in hochst seltenen Fullen syphilitische Iritiden auch in der Spätphase der Syphilis vorkommen können. Ich stimme sogar der Ansicht Mauthner's*) bei, dass Iritiden vorkommen können in den spätesten Phasen der Syphilis, wo alle anderweitigen consecutiv luetischen Producte bereits geschwunden sind, bei Individuen, wo man eigentlich fast berechtigt wäre zu sagen, dass Syphilis da war. Desgleichen führen Bull**), Förster***), Bäumler†), von Schröder $\dagger$ ) solche Fälle von verspatteten Iritiden auf, bezeichnen sie aber alle als höchst selten.

Ist eine solche späte Iritis nun als eine echte speeifische Iritis zu bezeichnen? Diese Frage möchte ich ganz entschieden mit nein beantworten. Es sind dies -- mit Ausnahme der später zu erwähnenden Fälle - nur Iritiden in einem syphilitischen oder syphilitisch gewesenen Individuum. Für einige dieser Fälle ist in Uebereinstimmung

*) 1. c. 59, p. 270 .

**) l. c. 9, p. $412-426$.

***) 1. c. 26, p. 188 ,

t) l. c. 13, p. 211.

†) 1. c. 97, p. 14. 
mit Bäumler der Ursprung der Entzündungsform in eine frühere Zeit zurückzuverlegen; die Ursache kann in alten Synechien gelegen sein, um so mehr da diese Iritiden nicht selten in ihrem klinischen Verhalten mit nicht syphilitischen chronischen Iritiden grosse Aehnlichkeit zeigen. Ich möchte ferner zur Begründung dieser Beobachtung vorläufig auch nicht den Standpunkt won Bäumler und Hutohinson annehmen und das gummöse Stadium gar nicht als specifischen Krankheitsprocess, sondern als Nachkrankheit bezeichnen. Bei dieser Annahme entfällt die Specifität dieser Iritiden dann von selbst.

Wenn ich auch für das gummöse Stadium die Specifität aufrecht halte, muss ich doch die in diesem Stadium sich ausbildende Cachexie des Gesammtorganismus hervorheben (Sigmund*), Zei ss l, Bäuml er**),Vi rohow**). Diese hat als solche jedoch nichts Specifisches, sondern sie ist nur durch ihr ätiologisches Moment von anderweitigen Cachexien different. Die Verschiedenheit der Aetiologie wirkt aber nicht bestimmend auf das Wesen der Cachexie und ihrer Producte. Letztere besitzen nichts Specifisches. Ebenso wie wir nach langwierigen Eiterungsprocessen eine amyloide Degeneration der Organe, wie Leber, Milz, Nieren, sich einstellen sehen, so gelangt nicht selten dieselbe Veränderung nach einer veralteten Lues zur Beobachtung. Kann dieselbe darum als eine specifische bezeichnet werden? Wahrlich nicht. Mit demselben Recht glaube ich, dass die seltenen, dem gummösen Stadium der Syphilis sich zugesellenden Iritiden wohl eher als Ausdruck der durch Lues bedingten Cachexie aufrufassen, nicht aber specifische Producte im wahren Sinne des Wortes seien.

Dass nach langwierigen Krankheitsprocessen, die wenn auch nur einen zeitweiligen Marasmus bedingen, Iritis auf-

*) 1. c. 100, p. 209 .

**) 1. c. 13, p. 25.

***) 1. c. 109 , p. 230. 
treten kann, ist Thatsache. Ich selbst habe solche Fälle nach schweren Typhen gesehen, in einem exquisiten Falle von Abusus spirituosorum, wo die erfolgte Section die amyloide Entartung der Leber, Milz und Nieren bestätigte. Bei 2 Fällen habe ich in Ungarn Gelegenheit gehabt zu beobachten, dass bei Individuen, die seit 2 bis 4 Jahren an Intermittens gelitten und der dadurch bedingten Cachexie unterlegen waren, Iritis aufgetreten war. Ich möchte übrigens bemerken, dass diese Iritiden in der Mehrzahl unter der chronischen Form auftreten, ebenso wie dies für diejenigen Iritiden constatirt werden kann, die in dem gummösen Stadium der Syphilis zur Beobachtung gelangen. Natürlich ist nicht ausgesehlossen, dass dieselben zuweilen auch acut anftreten, oder in Form eines acuten Nachschubes recidiviren.

Wenn wir nun auch den Einfluss der Therapie als mehr oder weniger mitberechtigt zur Entscheidung über die Specifität eines Entzündungsproductes heranziehen wollen, so lehrt die Erfahrung, dass die auf specifische Producte ziemlich prompt einwirkenden Mittel (Hg u. Jod) auch bei diesen in der Spätperiode der Syphilis eintretenden Iritiden in einer nicht geringen Zahl der Fälle im Stiche lassen. Ganz besonders ist dies bei blosser Anwendung von Mercurpräparaten zu sehen, ja gar nicht selten tritt bei ihrer energischeren Anwendung, wozu man sich durch Mangel eines Resultates sehr leicht verleiten lässt, sogar eine Verschlimmerung des Krankheitsprocesses ein. Viel günstigere Wirkung haben Jodpräparate, aber ich glaube, wohl mehr in ihrer Eigenschaft als roborirende Mittel, wie bei Anämie und Scrophulose. Diese Thatsache möchte ich jedoch nicht als bestimmt entscheidende hinstellen, ebensowenig, wie ich diejenigen Fälle nicht als entscheidend bezeichnen löonnte, wo Mereurpräparate eine günstige Wirkung aufweisen. Denn in nicht wenigen der Fälle mag Vireliow Recht hahen, dass ,manche Untersucher zu sehr 
geneigt im raschen Zusammenfassen alles der Syphilis zuzueignen, was nur irgend einer antisyphilitischen Behandlung weicht". Alles dies bestimmt mich, nochmals zu betonen, dass bei Beurtheilung der im gummösen Stadium auftretenden Iritiden die grösste Vorsicht gerechtfertigt sei.

Bekanntlich war Beer*) der Erste, welcher auf eigenthümliche Producte bei der syphilitischen Iritis mit den Worten hinwies: „es treten entweder am Pupillarrande oder am Ciliarrande der Iris, oder auf beiden zugleich rothbraune, höekerige Knötchen hervor". Beer nennt dieselben Condylome. Mit diesem Namen wollte er nicht das Wesen dieser Producte ausdrücken, sondern nur die angebliche äussere Aehnlichkeit mit den hahnenkammartigen Gebilden, „den spitzen Warzen" war es, was ihn bei Aufstellung dieses Namens geleitet. Derselbe wurde von den Nachfolgern Beer's angenommen und ist noch jetzt hie und da in Gebrauch. Da dieser Vergleich in den meisten Fallen unzutreffend ist, wird derselbe anch von neueren Autoren verlassen. So führt Arlt ${ }^{* *}$ ) sehr richtig an, dass diese gelblich-röthlichen Knötchen mehr den, „Tuberkeln“ gleichen, als den Condylomen der Cutis; v. Gräfe ${ }^{* * *}$ ) bezeichnet diese Producte als Nodi der Iris. Es handelte sich jedoch auch hier mehr darum, die äussere Aehnlichkeit besser zum Ausdruck zu bringen, als um einen Namen, der den Charakter und das eigentliche Wesen dieses Productes kennzeichnen sollte.

Virehow war es vorbehalten, als der Erste sich auch über das Wesen dieser ganz charalteristischen Producte der Iris des Näheren auszusprechen. Die erste Andeutung über diese Sache findet man in seinem Vortrage über constitutionelle Syphilis, wo er bemerkt, dass diese Knoten

\footnotetext{
*) 1. c. 7. I. B., p. 558.

*) 1. c. 2, p. 67 .

鈢) 1. c. 27, p. 209 .
} 
in der Iris wuchernde Gewebselemente und nicht Neubildungen seien. ${ }^{*}$ Viel bestimmter spricht er sich dann über diese "knotigen Auftreibungen" in seinen weiteren Arbeiten aus. Entgegen der bisherigen Ansicht stellt er sie als Wucherungs- and nicht als Exsudationsproducte dar [Arlt**), "plastische Exsudation"]. Virchow hat diese Bildungen als Analoga zu dem frühen Stadium des Gummigewächses aufgefasst und bezeichnet dieselben geradezu als Gumma der Iris ${ }^{* *}$ ). Ganz in diesem Sinne spricht er sich auch in der Onkologie aus $\dagger$ ), und zwar um so bestimmter, als seine frühere auf den klinischen Verlauf allein gegründete Muthmassung in der Zwischenzeit dureh pathologisch anatomische Thatsachen gestützt wurde, die eben in diesem Sinne gedeutet wurden.

Die nothwendigen pathologiseh-anatomischen Thatsachen wurden zunächst ron Alfred Gräfe und Colberg †) geliefert. Colberg theilt den mikroskopischen Befund von einem von Gräfe exstirpirten derartigen linsengrossen Tumor mit. Er sagt: „Unser Tumor glich also jenem früheren Stadium des Gummigewächses, wie es Virchow im Umfange der Käseknoten (in Hoden, Herz etc.) beschrieben hat und auch für die Iriscondylome aus dem macroscopischen Aussehen vermuthete. Ich glaube den mikroskopischen Nachweis geliefert zu haben, dass es eine gummöse Iritis im Sinne Virchow's giebt." Finen zweiten Befund haben wir v. Hippel $\dagger \dagger$ ) zu verdanken, wo die pathologisch-anatomische Untersuchung eines mit dem obigen als gleich angenommenen Tumors von Neumann vorgenommen wurde. Auf Grund der Ergebnisse dieser

*) 1. c. 108, p. 210.

**) I. c. 2, p. 67 .

****) l. c. 109, p. 307 .

†) l. c. 110, II. B., p, 462 .

†广) l. c. 30 , p. 288 .

t十t l. c. 38, p. 65 . 
Untersuchung wurde für diese Producte der Name Gumma substituirt, ein Name, der gleichzeitig als Ausdrucksweise für das Wesen und den Charakter dieser Producte gelten sollte.

Dio Ophthalmologen stimmen iber das, was sio als Gumma bezeichnen, nicht iuberein. Einige derselben verstehen unter Gumma nur diejenigen Producte, welche vollkommen den von Virchow beschriebenen analog sind. Es sind für gewöhnlich hirse- bis mohn- und linsengrosse oder auch etwas grössere, gelbrothe, braun bis braunrothe, uber das Nivean der Iris etwas erhabene knotige Auftreibungen, die ihren Sitz entweder am Ciliarrande oder an der Grenze zwischen kleinem und grossem Iriskreis, häufiger aber noch am Pupillarrande der Iris eimnehmen. Dieselben zeichnen sich durch ausgesprochenen Reichthum von Blutgefässen aus, die theils die Basis dieser kleinen Tumoren einnehmen, oder aber von da auf die Oberfläche derselben sich fortsetzend den Tumor geradezu umspinnen. Auf letzteres Verhalten namentlich möchte ich bei der Diagnose Gewicht legen. Im Gegensatze hierzu kennzeichnen andere 0 phthalmologen mit diesem Namen Producte, welche mit denen von Virchow als Gumma bezeichneten Gebilden nichts gemein haben.

Ich glanbe daher auch, dass die Ansicht einiger Antoren, das Gumma berechtige nicht stets zur Annahme einer luetischen Iritis, weil dieselben auch bei chronischen Iritiden vorkommen, grösstentheils auf nicht ganz genaue Beobachtung, beziehungsweise auf die Verwechslung ganz verschiedener Producte zurückzuführen sei. So beobachtet man bei chronischen Iritiden, dass mit der vorschreitenden Atrophie der vorderen Irisschichten and des eigentlichen Irisstroma, ein abnorm grosser Theil von der Pigmentschichte in Form eines die Pupille umgrenzenden breiten Pigmentsaumes sichtbar wird. Treten noch wie gewöhnlich hintere Synechien hinzu, so wird dies noch viel auf- 
fallender. Die Pigmentsehichte ragt dann in Form einzelner durch Pigmentwucherung oft ganz mächtiger Knöpfe in's Pupillargebiet herein. Solche, oft einen ganzen Kranz bildenden knötchenartigen Wucherungen der Pigmentschichte werden es wohl gewesen sein, die, namentlich wenn Lues da war, als Gumma angesehen wurden. Von den partiellen Anschwellungen ejnzelner kleiner Iristheile, die bei specifischer Iritis ziemlich häufig sind, bis zu den ausgesprochenen knotenartigen Producten sind ausserordentlich zahlreiche Zwischenstufen. Es hat daher hier oft subjectives Urtheil viel zur Verwechslung und Verwirrung der Begriffe beigetragen. So bezeichnet z. B. Alexander das an der Iris eventuell angesetzte Exsudat schon als Gumina. Ich halte daher die Streitfrage betreffs der Specifität der als Gumma der Iris bezeichneten Producte schon umsomehr für eine vorläufig ganz unfruchtbare, da wir auch noch in Bezug auf differentiell-diagnostische Momente der Gummata, Granulationsgeschwülste, leprösen Geschwülste, Tuberkeln, einzelner Sarcomformen [v. Gräfe*), Knapp $\left.{ }^{* *}\right), K i p p^{* *}$, Dreschfeld $\left.\left.\dagger\right)\right]$ keine stets sicheren Anhaltspunkte haben.

Welches Verhalten zeigt nun die Iritis gummosa zum allgemeinen Verlaufe der Syphilis? Der allgemeinen Anschauung gemäss sollte die gummöse Iritis in einer späteren Periode der Syphilis vorkommen. Diese Ansicht gründet sich zum Theile auf stricte Angaben einiger Autoren, anderseits, - und ich möchte dies betonen - auf den diesem Producte beigelegten Namen Gumma. Die den Oculisten bekannte Thatsache, dass Gummata Producte des gummösen Stadiums sind, bewog dieselben auch, dasjenige Gebilde, welches in der Iris mit diesem

\footnotetext{
क) 1, c. 29, p. 285 .

**) 1. c. 45, p. 131.

*; 1. c. 47, p. 177.

t) 1. c. 23 .
} 
Namen belegt wurde, in das gummöse Stadium einzureihen. Am entschiedensten von den neueren Autoren spricht sich darüber v. Wecker*) aus, der behauptet, dass die Iritis mit Knotenbildung in der Uebergangsperiode der secundären zu den tertiären Symptomen der Syphilis auftrete, und zwar bei Individuen vorkomme, wo auch die Haut Sitz schwerer dem gummösen Stadium angehörender Veränderungen sei (tubercules) ${ }^{* * *}$ ). Mooren***a äussert sich: "dass die Existenz der Gummaknoten der Iris in der Mehrzahl der Fälle auf tertiäre Syphilis hinweise. Von den Syphilidologen verlegt Bäumler $\dagger$ ) die Iritis gummosa nicht in das Stadium der allgemeinen Blutvergiftung, sondern in das Stadium der Nachkrankheit, daher in die Tertiärperiode. Bärensprung betrachtet im Gegensatze zur einfachen syphilitischen Iritis, die mit Tuberkelbildung einhergebende als ein Product der Spätphase der Syphilis. Viel reservirter äussert sich schon Förster + ), obzwar er auch der Ansicht ist, dass im Gegensatze zu den einfachen Iritiden die gummöse Iritis in einem etwas späteren Stadium der Syphilis zu erscheinen pflege. v. Gräfett+) selbst hatte anfangs eine Scheidung der luetischen Iritiden in secundäre und tertiäre vorgenommen und zu den letzteren rechnete er im Vereine mit den chronischen Iritiden auch diejenigen Formen, welche mit Bildung ron Nodi einhergehen. Später hat er dies jedoch fallen gelassen, da er ausdrücklich betont, dass er Uebergänge der einfachen Iritiden in Iritis gummosa beobachtet habe.

Ich will nun meine Beobachtungen mittheilen, die ich an den folgenden der Klinik des Hofrath von Arlt ent-

*) I. c. 101, p. 494.

**) I. e. 102, p. 361 .

***) 1. c. 58.1867, pe 140.

t) 1. e. 13, p. 190 .

t个) 1. c. 26, p. 189.

t+十 1, e. $2 \pi, 1,209$. 
nommenen Fällen durchgefübrt habe. Es sind diese durch Knotenbildung ausgezeichneten Iritiden demselben Materiale entnommen, wie die früher mitgetheilten einfach luetischen Iritiden. Ieh möchte hier gleich bemerken, dass meine Beobachtungen sich auch auf anderweitige nicht minder zahlreiche Fälle erstrecken, die alle das gleiche bestätigen, deren Mittheilang ich jedoch unterlasse, weil ich es für richtiger erachte, ein einheitliches Material als Basis zu benutzen (Vide klin. Tabelle II.).

Die knotenförmigen Producte der Iris sind durchaus keine häufige Begleiterscheinung der syphilitischen Iritiden. Nach den Angaben der Autoren stellt sich das Verhältniss folgendermassen dar:

$$
\begin{aligned}
& \text { Gesammtzahl Iritis gumm. In pot. } \\
& \text { der Iritiden. }
\end{aligned}
$$

\begin{tabular}{|c|c|c|c|c|}
\hline Schmidt, H.*) & 47 & 7 & 15 & pCt. \\
\hline Knapp**) & 26 & 5 & 19 & $"$ \\
\hline Coccius $* * *)$ & 42 & 5 & 12 & " \\
\hline v. Sehröder & 240 & 46 & 19 & $"$ \\
\hline Eigene Fălle †) & 59 & 11 & 19 & $\because$ \\
\hline & 414 & 74 & $\overline{17.8}$ & pct. \\
\hline
\end{tabular}

Es zeigt diese Zusammenstellung, dass drei der Angaben mit 19 pCt. in auffallender Uebereinstimmung sich befinden - von denen auch bei den zwei letzteren die grösste Beobachtungszahl vorliegt. Das Durchschnittsverhältniss ergiebt 17.8 pCt. Es wird daher dieses Verhältniss zwischen 17 -20 pCt. variiren, - demnach die

*) 1. e. 89, p. 273 .

**irsch, Centr.-Bl. II., p. 195.

***) 1. e. 18 .

†) 1. c. 97, p.

+1) Der 12. Fall der Tabelle II war ein ambulatorischer, konnte daher in diese Berechnung nicht mit einbezogen werden. 
Angabe von Mooren*) and Manthner**) auf $25 \mathrm{pCt}$. vielleicht etwas $\mathrm{zu}$ boch gegriffen sein mag.

Die von mir angeführte Zahl enthält sämmtliche an der v. Arlt'schen Klinik vorgekommenen Fälle von Iritis mit Knotenbildung - in dem oben angegebenen Zeitraume. Daron entfallen bezüglich der Zeitdauer vom Auftreten des Primäraffectes bis zum Entstehen der Augenerkrankung

$$
\begin{aligned}
& \text { 2-6 Monate . . in } 8 \text { Fällen } \\
& 6-8, \% \quad \cdots, 2, \\
& 1-1^{1 / 2} \text { Jahre . . " } 2 \\
& 12 \text { Fällen }
\end{aligned}
$$

Sämmtliche Fälle waren von solchen luetischen Producten begleitet, die unzweifelhaft dem condylomatösen Stadium angehörten; - und auch in den zwei Fallen, wo nach der Infection bereits ein Zeitraum von $1-1^{1 / 2}$ Jahren verstrichen war, handelte es sich nur um einen retardirten Verlauf der Syphilis, da auch bei diesen theils condylomata lata, theils reeidivirende papulöse Efflorescenzen vorhanden gewesen waren. Bemerkenswerth ist ferner, dass bei vier Fällen, wo das eine Auge an Iritis mit Knotenbildung erkrankt war, gleichzeitig das andere Auge an Iritis ohne Knotenbildung litt. In zwei Fällen $(11,12)$ war die einfache Iritis des einen Auges der Erkrankung des zweiten an knötchenförmiger Iritis vorausgegangen, im dritten Falle (Fall 9) erkrankten beide Augen gleichzeitig und nach einigen Tagen entwickelte sich $r$. das Knötehen; im vierten Falle (Fall 6) war die knötchenförmige Iritis des r. Auges nach 10 Tagen von einer einfachen Iritis des linken Auges gefolgt. Das zweite Auge wird daher unter der gewöhnlichen Form der syph. Iritis (ohne Knoten) ziemlich häafig in Mitleidenschaft gezogen, während eine doppelseitige

*) 1. c. 18, p. 252.

*) 1. c. 59, p. 139 . 
Iritis syph. mit Knotenbildung zu den Seltenheiten gehört. Dieses Verhalten gibt aber noch keine Berechtigung - wie es Bäumler*) thut - die knotenförmige Iritis mit Tertiärproducten in eine Reihe zu stellen, mit welch letzteren sie den Umstand gemein haben soll, dass sie keine Neigung zu symmetrischem Auftreten zeigt, denn auch die syphil. Iritis obne Knoten zeigt in der Mehrzahl der Fälle eine einseitige Localisation (unter 59 Fällen war nur 15 mal die Erkrankung doppelseitig) und doch rechnet auch $\mathrm{B}$ äumler diese Iritisform bestimmt zu den secundär luetischen Producten.

Dieses Verhalten der knötchenförmigen Iritis beweist zur Genüge die Unrichtigkeit derjenigen Ansicht, welche dieselbe als Localmanifestation der Spätphase der Syphilis kennzeichnet. Mit grosser Bestimmtheit weist die klinische Beobachtung nach, dass dieselbe dem condylomatösen Stadium angehört, und in der Mehrzahl der Fälle mit anderweitigen secundär-luetischen Producten zeitlich zusammenfällt.

Dass meine Beobachtung nicht vereinzelt dasteht, beweist schon die erwähnte Meinungsänderung v. Graefe's, wie auch die Angaben anderer Autoren. So finden wir bei H. Schmidt, trotz seiner Aeusserung, dass die gummöse Iritis in der Tertiärperiode vorkomme, Beobachtungen angefuhrt, die mit seiner Angabe nicht übereinstimmen. In 7 seiner Fälle von Iritis gummosa waren bei der Mehrzahl exquisite Frühproducte vorhanden; jedenfalls waren in keinem einzigen Falle bestimmte tertiäre Producte da. Mauthner**) giebt an, dass die Iritiden als erste unter den secundär-luetischen Manifestationen, oder aber gleichzeitig mit denselben erscheinen können, und dass sie zu allen diesen Zeiten mit Gummabildung verbunden sein

*) 1. c. 13, p. 28 u. 29 .

* $*$ l. c. 59, p. 270 . 
können. Mackenzie*) spricht sich in dieser Frage dahin aus: ,et qui sont généralement accompagnés on précédés d'une éruption syphilitique, sur le reste du corps". Ich glaube richtig an interpretiren, dass er wohl nur secundäluetische Producte gemeint hat. Aus den von Helbert ${ }^{* *}$ ) gemachten Mittheilungen wird ersichtlich, dass die ron ihm beschriebenen Exsudate bei der Iritis syphilitica - die er fälschlich als in allen Fällen vorhanden annahm -meistens nichts anderes als Nodi der Iris waren. Und er bemerkt, dass auch diese Iritiden gewöhnlich von secundärluetischen Producten begleitet waren. Mooren ${ }^{* *}$ ) selbst, der die Iritis gummosa für ein tertiär syphilitisches Product hält, erwähnt zweier Fälle, wo bei dem einen ein Gumma der Iris 6 Monate post infectionem auftrat, und bei dem zweiten gleichzeitig Psoriasis vorhanden war. v. Schröder †) constatirt, dass in keinem seiner 46 Fälle von Iritis gummosa sich tertiäre Symptome constatiren liessen, - wohl aber die Mehrzahl mit seeundär luetisehen Producten geradezu gleichzeitig auftrat. Die Zeit des Auftretens entsprach einem Zeitraum von $1 / 2-1$ Jahre post infectionem, das zeitliche Auftreten war demgemäss mit derjenigen der einfach luetischen Iritis übereinstimmend. Virchow十) selbst sagt: "Ich kann in Beziehung auf die Chronologie nur dem beistimmen, was fast alle Beobachter angeben, dass nämljch der Process (Iritis) regelmässig neben secundären Symptomen (Condylome und Syphiliden der äusseren Haut) vorkömmt, und ich bemerke besonders, dass ich auch die ,markig-knotige" Form unter denselben Verhältnissen sah.

\footnotetext{
*) 1. c. 56, p. 18 .

**) 1. c. 37, p. 105.

*水䉼) 1. e, 58, p, 139 .

t) 1. c. 97, p. 15 u. 16.

t) 1. e. 109 , p. 307 .
} 
Meine Beobachtungen sprechen unbedingt dafür, dass die mit Knotenbild ung verbundene Iritis, ebenso wie die ohne Knoten, eine Localmanifestation der Fruhphase der Syphilis ist. Das knotenförmige Product selbst kann daher nur als ein den anderweitigen secundär-luetischen Producten analoges aufgefasst werden. Die sogenannte Iritis gummosa ist nichts, als ein sich duroh Bildung eines specifischen Productes documentirender Steigerungsprocess der einfach specifischen Iritis. Die Knotenform der Iritis kann sich als solehe gleich in den ersten Tagen ihres Entstehens kennzeichnen oder sie entwickelt sich erst nach vorherigem Bestande einer einfach syphilitischen Iritis.

Wenn einerseits die klinisehe Thatsache feststehend ist, dass die knotige Form der Iritis ein Product des condylomatösen Stadiums sei, wir aber anderseits das in der Iris sich entwickelnde Product als Gumma bezeichnen würden, so würde dieses Verhalten der Iris zu dem sonstigen Verlaufe der constitutionellen Syphilis in vollem Gegensatze stehen. Denn es kann unmöglich angenommen werden. dass alle diese Fälle ron Syphilis mit knotenförmiger Iritis ohne Weiteres mit unter die höchst seltenen Ausnahmsfälle eingereiht werden dürfen, wo Uebergangsformen zwischen secundär und tertiär luetischen Producten vorkommen. So viele Ausnahmefalle sind sonst in dem naturgemässen Verlaufe der Syphilis absolut nicht zu beobachten; denn, wäre dies der Fall, so könnte man die Ausnalıme fast als Regel hinstellen. Dies ist aber entschieden nicht der Fall. Die Knoten in der Iris sind also keine Gummata, sondern syphilitische Papeln. Es ist daher auch nicht riehtig, wenn Virch ow meint „, die anatomische Form der secundüren Iritis sei derjenigen der tertiären Ostitis, 
Orchitis, Myocarditis" analog.* Die Iritis gummosa ist also eigentlich eine Iritis papulo sa.

Zur richtigen Erkenntniss eines Krankheitsprocesses sowohl als auch eines pathologischen Productes bedarf es zunächst einerseits der anatomischen, anderseits der klinischen Beweismittel. Ich will daher auch die knotenförmige Iritis sowohl vom anatomischen als klinischen Standpunkte etwas eingehender besprechen.

Was zunächst den anatomisehen Charakter dieser Nodi anbelangt, so wird derselbe sich klarer darstellen nach der Betrachtung des anatomischen Charakters luetischer Produete überhaupt, welche ich daher in kurzen Umrissen hier geben will.

Specifische Producte besitzen kein anatomisehes Charakteristikon, welches nur ihnen zukäme und sie als unabweisbar luetisch erkiären liesse. Dies geht schon daraus herror, dass selbst das Gumma histologisch Nichts darbietet, wodurch es über das Gebiet bekannter einfach-entzündlicher Producte hinausreichte, denn es ist "denkbar, dass eine analoge Form auch unter anderen Umständen entstehen könnte." (Virchow w**). Aus diesem Grunde schon ist die von Wagner***) aufgestellte Bezeichnung , Sy p hilom" in dem Sinne, ,dass eine specifischsyphilitische Neubildung existirt, ganz in derselben Weise wie os einen Tuberkel, ein Sarkom, ein Careinom $\mathfrak{u}$. s. w. von bestimmter Structur giebt", nicht berechtigt (Virchow $\dagger$ )). Weder die einzelnen, das Product bildenden Elemente, die Zellen und Kerne (Robin'sti), Cystoblasten", auch Vernenil †t) noch aber ihre eigenthümliche Anordnung (Wagner's alveolenartige Einlagerung) oder überhaupt das Verhältniss der Elemente unter einander und zu der umliegenden Substanz, sind so charakteristisch, dass sie mur den Gummaprodukten zukämen. Die "Gesammteinrichtung" des Gumma, wie dies Virchow be-

*) 1. c. 109, p. 307 .

\%) l. c. 109, p. 320 a l. c. 110, p. 392.

* l. c. 111, p. 2.

†) 1. c. 109, p. 221 u. 325 , l. c. 110 , p. 393.

†) 1. c. 76 a. 77 .

晻方 l. c. 107, p. 177 . 
zeichnet, bietet zwar jedenfalls viel mehr Eigenthümlichkeiten dar, als dessen einzelne Elemente, ist aber ebenfalls nicht bestimmend. Mögen die luetisehen Producte klinisch noch so different sein, sie zeigen stets die gleiche kleinzellige Wucherung, welche namentlich, wenn auch nicht ansschliesslich, aus der bindegewebigen Matrix hervorgeht. Diese Gleichmässigkeit des anatomischen Befunds bestimmt den Anatomen, nur ein einziges Product der Lues anzuerkennen, ein syphilitisches Gebilde überhaupt. Die anatomische Untersuchung ist nicht im Stande, eine Papel ron einem Gumma, dieses ron einer Initialsclerose auseinanderzuhalten. Alle zeigen die gleiche kleinzellige Infiltration. (Lebert*), Bull**), Wagner, Virchow.) Bei den papulösen Syphiliden findet sich dieselbe Zelleninfiltration, wie bei den sonstigen, gummösen Producten (Birch-Hirschfeld***), Bärensprung $\dagger$ )). Das breite Condylom (plaque muqueuse) ist anatomisch anch eine kleinzellige gummöse Infiltration, die vorzugsweise den Papillarkörper und die oberen Cutisschichten betrifft. Die primär syphilitische Induration entspricht vollkommen dem Bilde der gummösen Neubildung (Birch-Hirschfeld †t)) oder noch prägnanter ,in den Gummositäten wiederholt sich die Induration des Mutterknotens".+†t)

Wenn auch das Obige als die einzige von der Anatomie gelieferte positive Thatsache anerkannt werden muss, so möchte ich doch auf einige, wenn auch nicht wesentliche Verschiedenheiten aufmerksam machen, die bei Beobachtung verschiedenartiger luetischer Producte nachweisbar sind. Was zunächst die Härte der primären Sclerose anbelangt, so weist Biesiadecki* ) namentlich auf das eigenthümlich starre Gefüge der Sclerose im Gegensatze zu anderen luetischen Producten hin, das wohl einerseits in einer fester gefügten Faserung des Bindegewebes, anderseits in der gedrängten Anordnung der die Infiltration bedingenden kleinzelligen Elemente seinen Grund haben mag. Durchaus nicht in diesem Maasse ist dieses Ver-

*) 1. c. 54, p. 361 .

*) Bull, Würzburger Med. Zeitschr. 1859 III. B.

类粠) 1. e. 15, p. 650 .

f) l. c. 11, p. 6 .

H) 1. e. 15, p. 648 .

Ht广) 1, e. 110 , II. B. p. 473 .

*) 1. c. 14 . 
halten bei secundär luetischen Producten zu beobachten. Hier mangelt die starre Rigidität des Productes gänzlich. Wir haben es vielmehr mit dem anatomischen Befunde einfacher Granulationswucherung zu thun. Eine solehe Differencirung ist aber zwischen Gumma und secundär luetischen Producten in noch viel höherem Grade nachweisbar. Schon Bärensprung*) hebt den Unterschied hervor, dass secundär-luetische Producte wesentlich Hyperämien und einfache Exsudationen, die tertiäre Periode mehr Neubildungen ähnli he Producte (Tuberkel) hervorbringe, - welcher Ansicht auch Zeissl sich anschliesst. In dieser Beziehung stellt übrigens auch Virchow**) einen Unterschied auf, indem er bei den luetischen Producten zwei Reihen von Neubildungen muterscheidet. Zunächst solche, die sich anatomisch den hyperplastischen (einfach entzündlichen) Formen anschliessen, mehr den gesetaten einfach formativen oder nutritiven Reizungen entsprechen und demgemäss leichtere Producte, - wie dies clie secundär-luetischen sind - hervorbringen. Im Gegensatze zu diesen stehen die schwereren gummösen Producte, die mehr Analogie mit eigentlich specifischen Irritationen haben. Während die ersteren mehr zur Bildung homologer Gewebe führen, haben wir es bei letzteren mit mehr heterologen Bildungen zn thun. Virchow betont anch, dass es zur Bildung gummöser Producte schon einer gewissen Energie und Höhe der speeifischen Substanz bedürfe, um solche exquisit-specifisehe Producte heranzubilden.

Den grössten anatomischen Unterschied bieten jedoch die verschiedenartigen luetischen Producte einerseits betreffs des Verhaltens der Blutgefässe, anderseits bezüglich der regressiven Veränderungen dar. Was zunächst das Verhalten der Blutgefässe anbelangt, so findet man bei Sclerose (Biesiadecki***) die grösseren Gefässe mit an dem Krankheitsprocesse betheiligt. Bei intactem oder selbst erweitertem Lumen ist die Adventitia von Zellen durchsetzt, verdickt. Die Capillaren hingegen zeigen bei Verdickung der Wand gleichzeitig ihr Lumen verschlossen; sie haben ein ganz starres Aussehen. Dieselben sind theils durch die Umgebung, theils durch ihre eigene Erkrankung

*) 1. c. 12, VI. B., p. 56 n. VII. Bd., p. 173.

**) 1. c. 109, p. 320 u. ff. 1. c. 110 II. B., p. 394.

****) 1. c. 12 . 
comprimirt. In gewissem Grade ist ein Gleiches bei den Lymphbahnen zu beobachten, wie dies von Hughier und Basserean angegeben wurde*).

Bei secundär-luetischen Producten, wie es maculopapulöse oder papulöse Syphilide, Condylomata lata sind, ist gleichfalls eine Erkrankung der Gefässwände, namentlich der Adventitia zu beobachten. Man findet eine Wucherung der zelligen Elemente; dagegen participiren die Capillaren an dem Wucherungsprocesse nur in höchst geringem Masse und stets ist das Lumen derselben offen, ja meistens erweitert. Man kann deutliche Gefässüberfüllung beobachten, ja Andeutungen, die als Gefässneubildungen anzusprechen sind (Günsburg**).

Was nun das Gumma anbelangt, so ist es namentlich im Verhältnisse zu secundär-luetischen Producten durch die Armuth an Gefässen auffallend (Lebe rt****). Das weitere Verhalten desselben steht zu dem bei der Sclerose gegebenen Befunde in Uebereinstimmung. Man findet überall die etwa vorhandenen Capillaren in einem gleichen Zustande wie bei der Sclerose, sie sind in hohem Grade comprimirt, ja geradezu verödet. „Die Capillaren scheinen eine fibröse Umwandlung eingegangen zu sein" (Wagner).

Was nun die weitere Metamorphose anbelangt, welche Iuetische Producte eingehen, so berufe ich mich auf Virchow †), der dieses Verhalten als eine der wesentlichsten Eigenthümlichkeiten derselben betont. Die luetischen Producte bestehen gerade im Gegensatze zu den mehr ein Dauergewebe bildenden einfach bindegewebigen Granulationen ans Elementen transitorische $x$ Natur, mit Neigung zu frühem Zerfall. Ihr Untergehen ist daher gleichsam das Regelmässige und der nothwendige Beschluss ihrer Existenz. Die Art der regressiven Metamorphose ist bei secundär- und tertiär-luetischen Producten sehr verschieden.

Beim Gumma erfolgt das Absterben des Gewebes durch fettige Metamorphose der einzelnen Elemente, welche in grosser Ausdehnung stattfindet. Jedoch kann diese Metamorphose, wahrscheinlich in Folge derberer Beschaffenheit des Inter-

*) 1. c. 112 .

**) Günsburg. Nene Zeitung für Medicin und med. Ref. No. 72 u. 73,1849 und Schmidt's Jahrb.

**at) L. e. 54, p. 370 .

†) 1. c. 110, II. B. p. 393 . 
stitialgewebes and des dadurch bedingten unvollständigen fettigen Zerfalles einen mehr käsigen Charakter annehmen. Und gerade dieses a asige Material ist als Ausgang der Gummata wesentlich. „Nichts charakterisirt das Gummagewächs mehr als diese gelben frühe todten Massen (Caput mortuum), welehe oft noch von jungem zellen reichem wucherndem Gewebe nmgeben sind.*)" Alle diese Processe verlaufen im Gumma in charakteristiseh langsamer, träger Weise: das Ende des käsigen Zerfalles ist entweder Ausstossung durch Eiterung oder Eindickung; in jedem Falle mit nachfolgender Bildung von Narbengewebe. Am meisten Aehnlichkeit mit dem Gumma zeigt in dieser Beziehung die Initialsclorose. Jedoch sah ich bei letzterer den fettigen Zerfall der zelligen Elemente nie in so grosser Ansdehnung wie bei Gumma. Die Fettmetamorphose scheint im Gegensatze zu dem Gumma, wo dieselbe fast gleichzeitig einen grossen District betrifft, hier mehr schubweise vor sich zn gehen, und demgemäss ist auch verhältnissmässig nur oine geringe Zahl fettig entarteter Zellen vorhanden.

Wesentlich verschieden gestaltet sich die regressive Hetamorphose bei den Producten des condylomatösen Stadiums. Man findet bei denselben einen von jungem zelligem Gewebe gebildeten Heerd, mit einer Anzahl theils in Theilung begriffener, theils bereits fettig zerfallender Zellen. Nie sieht man Anzeichen der für Gumma so charakteristischen käsigen Metamorphose. Die fettig entarteten Zellen bilden nieht eine gesonderte Gruppe, sondern sind vielmehr in dem succulenten zellenreichen Gewebe zerstreut. Dass es nicht zur Bildung grösserer fettiger oder käsiger Heerde kommt, hat theils in der leichteren Resorbirbarkeit der einzelnen zerfallenden Zellen, theils in dem Vorbandensein zahlreicher gnt functionirender Abflusswege, weiche die Zerfallsproducte abführen, seinen Grund.

Ich habe auf das Verhalten der Blutgefässe einerseits, auf die Art der regressiven Metamorphose anderseits hingewiesen, weil sich dieselben bei secundär- und tertiär-luetischen Producten höchst verschieden verhalten, so dass diese beiden Momente einen, wenn auch nicht absolut sicheren Leitfaden bei Differencirung secundär- und tertiär-luetischer Producte abgeben können. Diese beiden Momente stehen in einem

*) l. c. 110, p. 400 u. ff. 
innigen Abhängigkeitsverhältnisse. Das Terhalten der Blutgefässe scheint den weiteren Verlanf des Lebens dieser Producte zu bestimmen, insofern sich darnach die Involution derselben gestaltet.

Ich verlasse nun das anatomische Gebiet, um auf die Resultate klinischer Beobachtung überzugehen. Dieselbe weist zunächst bei secundär-Iuetischen Producten eine grosse Energie des Auftretens nach, indem sie schnell erscheinen, oft unter entzündlichen Erscheinungen verlaufen und ebenso rasch schwinden. Das Gumma hingegen zeichnet sich durch seinen höchst trägen Verlauf aus. Während die gummösen Producte sich als abgegrenzte, von neugebildetem Keimgewebe umgebene, oder geradezu eingebettete, mehr oder weniger kugelige Knoten darstellen, bieten die secundären Producte ein wesentlich differentes klinisches Bild. Sie zeigen schon im klinischen Bilde einen bedeutenden Reichthum an Blutgefässen. im Gegensatze zu den höchst gefässarmen gummösen Producten. Erstere bieten in ibrer vollen Entwicklung auch ein mehr den entzündlichen Processen annäherndes Verhalten, während die Gummata mehr den Typus ron Neubildungen besitzen. Der entzündliche Charakter der Localstörung tritt bei den Frühformen der Syphilis derart in den Vordergrund, dass Bärensprung *) die verschiedenartigen luetischen Exanthemformen als „entzündliche schlechtweg" bezeichnet. Was das Verhalten luetischer Producte in ibrem weiteren klinischen Verlaufe anbelangt, so sind die Frühformen geradezu als schnellverlaufende $z u$ bezeichnen, im Gegensatze zu Spätformen, für die ein geradozu unverrïcktes Stillstehen auf der Grenzscheide zwischen Organisation und Zerfall charakteristisch ist [Rindfleiseh**)]. Thre energisehere Lebensthätigkeit kennzeichnet sich auch in ihrem Endstadium gegenüber der Chronicität der Gummata.

Die Frühformen der Syphilis sehwinden in der Mehrzabl der Falle ziemlich rasch durch vollkommene Resorption und fast nư in Folge äusserlicher sehädlicher Einflüsse können dieselben auch zerfallen. Jedoch auch dann zerfallen die solchen Einflüssen am meisten ausgesetzten Condylome in der Regel nicht im Centrum, sondern ulceriren oberflächlich und von da aus schreitet die Ulceration erst in die Tiefe. Es geschieht

;) l. c. 11, p. 238.

*) l. c. 81, p. 27 . 
dies im Gegensatze zu gummösen Producten, wo der im Grossen auftretende fettige Zerfall rom Centrum ausgeht. Der eitrige Zerfall secundär-luetischer Producte kann fast ausschliesslich nur soleh' äusserlich schädlichen Momenten zugeschrieben werden, da „es geradezu zum. Wesen einer Papel gehört, dass sie stets im festen Aggregationszustande verharrt" [Ze is sl $\left.{ }^{*}\right)$ ]. Und wenn dieselben überhaupt zerfallen, so ist dies mehr ein ganz aberflächlicher eitriger Zerfall, und fast nie enden sie ihr Dasein durch totale Vereiterung. Im Gegensatze hierzu findet der eitrige Zerfall der Gummata nach erfolgtem, für gewöhnlich vom Centrum ausgehendem fettigen Zerfalle der Elemente, in Form eines tiefgreifenden Ulcerationsprocesses statt. Nie sah ich bei Frühformen der Syphilis die für Gummata so charakteristische küsige Metamorphose eintreten. Die vollständige Resorptionsfähigkeit secundär luetischer Producte ist in ihrem ganzen Wesen wohl begründet, so dass es selbst dann nicht zur Bildung irgendwie erheblichen Narbengewebes kommt, wenn dieselben in Folge schädlicher Einflüsse einen oberfächlichen eitrigen Zerfall eingegangen sind. Im Gegensatze hierzu sind die gummösen Producte stets von einer derben schwieligen Narbe gefolgt, mögen sie durch eitrigen Zerfall oder käsige Netamorphose zu Grunde gegangen sein.

Wir ersehen hieraus, dass nicht nur schon in den ersten Stadien die grosse Mannigfaltigkeit der pathologisch-anatomischen Krankheitsbilder im grellen Gegensatze steht zu der Monotonie und Einfachheit der mikroskopisehen Bilder [Rindfle $\left.\mathrm{seh}^{* *}\right)$ ], sondern dass dies anch in dem gesammten weiteren Verlaufe der luetischen Erscheinungen als solche der Fall ist. Immerhin glaube ich, dass hier anch noch unsere heutigen, vorläufig ziemlich mangelhaften anatomisehen Hilfsmittel und Kenntnisse nicht ausser Acht gelassen werden dürfen, welche mit daran Schuld tragen, dass die Anatomie naturgemäss so differente Producte wie Papel und Gumma nicht zu unterscheiden vermag.

Wenn ich bei der nun folgenden anatomischen Betrachtung des von der Iris sich bildendenden luetischen

*) 1. e. 114, p. 110 .

) 1. c. 114, p. 238. 
Productes auf das im Allgemeinen Gesagte verweise, so bin ich doch weit entfernt, alle eben angedeuteten anatomischen Verhältnisse ohne weiteres auch auf diese Irisproducte zu übertragen. Bei syphilitischen Producten ist es in hohem Grade die Matrix, welche in Berücksichtigung gezogen werden muss, weil sie deren spätere Geschichte mitbestimmt. Ist dies nun überhaupt der Fall, so muss umsomehr anerkannt werden, dass die Berücksichtigung des Mutterbodens bei Irisgeschwülsten [HirschbergSteinheim*)] von noch höherem massgebenden Interesse ist. Immerhin glaube ich, gestützt auf die Richtigkeit des Ausspruches von Virchow ${ }^{* *}$ ), dass die Gummigeschwulst wohl so sehr specifisch, dass wir unsere Kenntnisse von der Leber- oder Hodensyphilis einfach auf die Lungen oder das Gehirn übertragen können, - diese Kenntnisse auch auf die als "Gumma" der Iris bezeichneten Producte, wenn auch nur vergleichsweise übertragen werden dürfen. Die wesentliche anatomische Uebereinstimmung luetischer Producte überhaupt, berechtigen dann übrigens zur Anwendung dieses Principes gewissermassen auch bei der Betrachtung secundär-luetischer Producte.

Bei Geschwülsten der Iris ist die anatomische Differenzirung in hohem Grade beschränkt. Wir finden dies allseits bestätigt. So fand Virchow in einem vonv. Graefe $e^{* * *}$ ) mitgetheilten Falle, "dass der kleine markige Knoten sehr wohl eine Gummigeschwulst sein kann", während Billroth auf Grund des Befundes von Granulationsgewebe, mit massenhafter Verfettung und Myeloplaxen (plaques à noyaux multiples) - dasselbe Product als eine ,hochorganisirte Granulationsmasse" bezeichnet. Da auch Lues congenita nicht nachweisbar war, hat daher v. Graefe

\footnotetext{
*) 1. c. 39, p. 151 .

\%) 1. c. 109, p. 325.

***) I. c. 28, p. 39 .
} 
diesen Fall "als einen dyscrasischen, wenn auch nicht syphilitischen Krankheitsprocess derIris aufgefasst. Weeker*) rechnet diesen Fall zum Gumma der Iris, während Hirsch berg und Steinheim dies als unzweckmässig bezeichnen, und es meint namentlich Ersterer, dass, wenn auch Granulationsgeschwülste mit dem Gumma der Iris histologisch übereinstimmen, die Differenzirung vom ,practischen Standpunkte" sich empfehle. Darauf wäre auch die von ihm aufgestellte Benennung "Granuloma specificum, syphilitioum", zurückzuführen. Haab rechnet den eben erwähnten Fall wieder zur Tuberculose der Tris. Anderseits, da auch Granulationsgeschwülste gegenüber gewissen Sarcomformen [Hirschberg und Steinheim**)] geringe histologische Differenzen darbieten, so ergiebt sich auch hieraus schon die höchste Schwierigkeit, die sich in manchen Fällen der anatomischen Entscheidung entgegenstemmt. Es muss immer wieder nur die reine klinisehe „SpecialDrfahrung" mit herangezogen werden. Letzteres ist geradezu bei Irisgeschwülsten das wesentlich entscheidende Moment, und wird als solches auch von Schnütgen ***) anerkannt, in einem von ihm mitgetheilten Falle von Granulom; wie anch von $\mathrm{Haab}+$ ) angegeben wird, dass in die eine von ihm aufgestellte Reihe von Tuberculose (Granulom) der Iris nur Falle untergebracht werden dürfen, in denen sich Syphilis mit Sicherheit ausschliessen lässt. Der klinische Nachweis über das Vorhandensein der Syphilis kann allein in solchen Fallen den Ausschlag geben.

Von anatomischen Befunden äber Knoten in der Tris liegen zwei Beobachtungen vor. Von diesen wäre eigentlich nur allein der von Alfred Graefe und Colbergt十)

*) Wecker, Etud. ophth. II. T., p. 430.

*) 1. c. 39, p. 151 .

**i*) 1. c. 91.

t) 1. c. 42, p. 193.

t) 1. c. 30. 1. A., p. 288. 
mitgetheilte hierhergehörig, indem nur da das knotenartige Product in der Iris primär auftrat und auf dieselbe beschränkt blieb. Der zweite Fall von v. Hippel und Neumann *) bietet nicht mehr ein ganz reines klinisches Bild der sogenannten Iritis gummosa. Graefe's Fall betrifft einen linsengrossen Tumor unzweifelhaft syphilitischen Ursprunges. Der mikroskopische Befund stellt nun ausser allen Zweifel, dass wir es mit einer kleinzelligen Infiltration in dem Gewebe der Iris zu thun haben. Der Tumor bestand der Hauptmasse nach aus kleinen Zellen. Dieselben waren theils stern- und spindelförmig, den Bindegewebszellen der Iris analoge Gebilde, theils Elemente, welche aus einer Wucherung des Bindegewebes selbst hervorgegangen waren. Ausserdem ergab sich ein auffallender Reichthum an Capillaren, ja sogar sichere Andeutung neugebildeter Gefässe. Die Capillaren waren auch dort, wo die vorhandene Zellenwucherung von der Adventitia (His) ausgegangen sein mochte, vollkommen durchgängig, das Lumen derselben mit Blut überfültt. Fin fettiger Zerfall war nirgends eingetreten.

Aus diesem Befunde glaube ich schliessen zu dürfen, dass der untersuchte Knoten in der Iris eine syphilitische Papel gewesen sei. Denn zunächst tritt der entzündliche Charakter dieses Productes ebenso wie des ganzen Krankheitsprocesses mehr in den Vordergrund. Ferner war dieses Irisproduct in seinen Elementen denen des Mutterbodens homolog; es muss daher das Resultat des specifischen Virus in jener Entwicklungsphase der Syphilis sein, wo derselbe nur dazu befähigt so zu wirken wie der Theil an sich eingerichtet. Das heisst, die Syphilis befindet sich bei Producirung dieser Nodi im condylomatösen Stadium. Der anatomische Befund weist ferner einen auffallenden Reichthum an Capillaren, sowie Neabildung von Gefassen

*) 1. c. 38. 1. A. p. 65. 
nach, endlich auch Wucherung der Capillarwand, nebst gleichzeitigem Erhaltensein ibres Lumens, geradeso wie in der Papel.

Was die regressive Metamorphose anbelangt, so war bei diesem Producte die für Gumma charakteristische Neigung zu fruhem Zerfall nicht einmal andeutungsweise vorhanden. Im Gegentheil, das Product zeigte rege Proliferationsvorgänge, da Colberg sich ganz bestimmat von "einer Einschnürung oder Finkerbung" an den Kernen ubberzeugen konnte (beginnende Theilung), ein Vorgang, der jedenfalls bei einer solchen Entwicklungshöhe, wie es der gegebene Tumor zeigte, nicht als Zeichen der Trägheit und der Neigung zum raschen Absterben der Elemente gedeutet werden kann.

Wenn ich alles dieses zusammenfasse, so glaube ich wohl zur Annahme berechtigt zu sein, dass bei dem Graefe'schen Falle der anatomische Befund mit viel grösserer Berechtigung dafür spricht, dass wir es mit einem Producte des condylomatösen Stadiums, einer syphilitischen Papel als mit einem Gumma zu thun haben.

Der zweite von v. Hippel und Neumann veroffentlichte Fall war nicht eine reine Iritis gummosa. Die Iris participirte nur secundär an der Erkrankung der Nachbargewebe des Auges. Die genauere Einsicht des anatomischen Befundes wird darlegen, dass derselbe dem des ersten Falles gegenüber gestellt werden muss. Der anatomische Ban wies im Grossen und Ganzen eine kleinzellige Infiltration auf. Es kam aber dabei zur Entwickelung von Elementen, welche mehr als heterol oge bezeichnet werden können. Wir sehen eine weit gediehone Verfettung der Elemente, welche in das betreffende Muttergewebe eingebettet erscheinen. Dieses Product nähert sich, ist vielleicht schon sogar volllommen analog denjenigen Producten, die ihre Entstehung ,der vollen Einwirkung des specifischen 
Virus" verdanken, wie dies $\mathrm{Tirchow}{ }^{*}$ ) für gummöse Producte betonte. Dieses Product ist als Resultat des zu einer solchen Grösse und Energie gediehenen Reizes anzusprechen, welche das specifische Virus erst in der tertiären Entwickelungsperiode, im gummösen Stadium, zu erlangen vermag.

Berücksichtige ich noch die aus der klinischen Beobachtung dieser zwei Fälle sich ergebenden Thatsachen wenn dieselben auch rom Standpunkte der constitutionellen Erkrankung ziemlich mangelhaft -, so wird aus denselben Folgendes ersichtlich. Graefe's Fall betraf einen 24 jahrigen Kranken von sonst blühendem Aussehen, der nach wiederholten (?) syphilitischen Infectionen, im Laufe einer floriden Syphilis von knötchenförmiger Iritis des rechten Auges befallen wurde. Bei dem Kranken von v. Hippel war zwischen dem Auftreten der Angenerkrankung und dem Primäraffecte bereits ein Zeitraum von 2 bis $2 \frac{1}{2}$ Jahren verstrichen, Es ist dies ein Zeitraum, der erfahrungsgemäss die constitutionelle Syphilis befahigen konnte, gemäss der erlangten Hohe und Knergie des specifischen Virus gummöse Producte hervorzubringen.

Wenn ich nun den anatomischen Befund des Graefe'schen Falles damit zusammenhalte, was die Zusammenstellung der von mir beobachteten Iritisfulle ergeben hat, so komme ich zu dem Schlusse: dass das knotchenformige Product bei der sogenannten Iritis gummosa kein Gumma sondern eine Papel ist. Zur weiteren Bestatigung dieser Ansicht will ich noch das Entstehen, Aussehen and die Involution des Productes betrachten, da diese die wichtigsten klinischen $\mathrm{Be}-$ weismittel enthalten, welche den Charakter eines luetischen Productes bestimmen. Die Entstehungsweise dieser knotenförmigen Producte weist auf den exquisit entzünd-

*) 1. c. 110. II. B. p. 403 . 
lichen. Charakter des stattgehabten Processes hin, als dessen Resultat diese Nodi aufgefasst werden müssen. Wenn die Entzündung auch nicht stets die Iris in ihrer Totalitat betraf, so war doch wenigstens an derjenigen Stelle, wo das Product sich etablirte, eine circummscripte Irispartie geschwellt, gelockert, mit feinen Gefässchen reichlich versehen. Nie habe ich die Entzündung gänzlich fehlen gesehen, wie dies Mooren ${ }^{*}$ ) angiebt. Für gewohnlich kam es auch zur Bildung einer mehr oder weniger mächtigen hinteren Synechie, Anzeichen, die sicherlich auf Exsudation hindeuten. Die Zeitdauer nun, in welcher diese Nodi ihre vollständige Entwicklung erreichten, ist, abgesehen von den seltenen Ausnahmsfällen der mehr als linsen- bis erbsengrossen Tumoren, für die weitans grösste Mehrzahl der Falle als eine kurze zu bezeichnen.

Was die Entwicklungsweise dieser knotenförmigen Iritis betrifft, so kann sich dieselbe entweder gleich im Beginne ihrer Entstehung als solche kennzeichnen, oder aber es kommt erst zur Bildung des knotenartigen Productes, nach mehr oder weniger langem Bestande einer einfachen specifischen Iritis. Jedoch auch in letzterem Falle ist die Entwicklung der Nodi als eine rasche zu bezeichnen. Fast stets sah ich an dem betreffenden Iristheile, wo es zu einer nachträglichen Entwicklung der Nodi kam, eine deutlich ausgesprochene Ueberfüllung der vorhandenen and Bildung neuer Gefässe, welche Veränderungen sich beim Sichtbarwerden des Knotens noch steigerten. Selten sah ich nach einem Zeitraum von 10-12 Tagen diese Knötchen noch weiter an Grösse zunehmen, sie scheinen vielmehr innerhalb dieser Zeit ihre vollständige Entwicklung erreicht zu haben. Es stellt diese Entwicklungsart den Uebergang der einfach syphilitischen Iritis in die mit Knötchenbildung einhergehende Form dar.

*) 1. c. 58, p. 139. 
Für den acuten Charakter dieser Producte sprieht auch die für gewöhnlieh durch einige Zeit vorher sich einstellende Steigerung sämmtlicher Entzündungserscheinungen seitens der Iris, falls es zur Bildung dieser Nodi kommt. Es gleicht dies in gewissem Sinne der schon von Virchow vermutheten Thatsache, welche übrigens auch bei anderweitigen Syphiliden, wenn auch weniger auffallend, zu beobachten. Es erfolgt eine Art Nachșchub ron specifischem Virus und darauf folgende neuerliche gesteigerte Lebensthätigkeit desselben. Eine ganz entsprechende Entwicklung lässt sich übrigens auch bei anderen secundären Syphiliden beobachten. Nicht selten kommt es anf dem Boden eines Erythema maculosum oder maculo-papulosum zur Bildung mächtigerer luetischerProducte, zurEntwicklung eines exquisit papulösen Syphilides. Dieser Uebergang der verschiedenartigen Formen der Syphiliden, der einfacheren und leichteren in die mächtigeren, ist nur bei Frühformen zu beobachten. Nie sah ich jedoch eine noch so entwickelte Riesenpapel in ein gummöses Product ubergehen. Ebenso nun wie dies nie geschieht, ebenso wenig kann ich die Möglichkeit zugeben, dass eine einfach syphilitische Iritis, die unbedingt eine Frühform der Lues ist, je in eine gummöse Iritis übergehe.

In einer zweiten Reihe von Fällen, - den vielleicht häufigeren, - wird, wie bereits erwähnt, die Iritis gleich vom Anbeginn ihrer Entstehung sich als eine mit Knotenbildung einhergehende manifestiren. Auch da erlangen die Nodi ihre vollständige Entwicklung in einer entsprechend geringen Zeit. Möge aber die Entwicklung dieser Iritisform nach welcher der beiden Arten immer vor sich gehen, jedenfalls tritt der entzündliche Charakter der Localstörung ganz deutlich hervor, und es bezeichnet ja auch Virchow*) dieselben als acut sich entwickelnde Knoten.

*) 1. e. 109 , p. 305. 
Was das Aussehen der knotenartigen Producte betrifft, so sind sie zumeist mohn- und hanfkorn-, bis linsen- und Kleinerbsengross. Die Grösse derselben ist übrigens in Bezug auf die Entscheidung ihres Wesens ganz irrelevant. Für gewöhnlich sah ich, dass diejenigen Nodi, welche näher dem Ciliarrande der Iris auftreten, eine etwas mächtigere Entwicklung erlangen. Vielleicht dass diese Theile der Iris zu ihrer Grössenentwickelung einen günstigeren Boden abgeben. Es finden sich übrigens auch bei anderweitigen Syphiliden, namentlich der äusseren Haut, Prädilectionsstellen, wo dieselben eine besonders mächtige Entwicklung erreichen. Es wird beobachtet, dass ein anfangs lenticulär-papulöses oder auch miliar-papulöses Syphilid an manchen Orten Geneigtheit zeigt, sich zu einer: sogenannten Riesenpapel zu entwickeln, wie dies z. B. namentlich an den Augenlidem der Fall ist. Die Farhe der Irisknoten ist gelblich, gelbroth, dunkelgrau bis dunkelbraun und rothbraun. Diese Farbe ist in ihrem Reichthume an Blutgefässen begründet. Im Ganzen stellt sich daher das knötchenförmige Product der Iris als eine mehr oder weniger grosse, über die Irisoberfläche entweder mehr flächenartig (lenticuläre Form) oder mit mehr kolbiger oder kegeliger Spitze hervorragende tuberkelartige Exerescenz (miliare Form) dar, welche einen ganz ausgesprochenen Reichthum an theils vom Irisstroma übergehenden, theilweise neugebildeten Gefässen zeigt und demgemäss von gelbrother bis dunkelbrauner oder rothbrauner Farbe ist.

Wie verhalten sich nun diese Nodi der Iris in Bezug auf ihre Involution. Die Art der Involution luetischer Producte ist klinisch schon so charakteristisch, dass sie oft genug als Beweis herangezogen werden muss, behufs Eutscheidung dessen, ob das Product der Früh- oder Spätphase der Syphilis angehört (Zaissl*). Die Involution

*) 1. c. 115 . 
der Irisknoten geschieht auf dem Wege der einfachen Resorption. Dieselbe kamn eine so vollständige sein, dass absolut Nichts mehr an das einstige Vorhandensein der Knoten erinmert, ja nicht einmal die Stelle an der Iris, an welcher diese sassen, dureh irgend etwas gekennzeichnet bleibt. Oder aber die Resorption ist wohl eine totale, aber es bleibt eine meistens etwas breitere hintere Synechic zurück, jodoch auch dann noch kann der Mutterboden dieses Productes seine vollständig normale Beschaffenheit beibehalten haben. Nur in einzelnen Fällen kommt es zur leichten Auffaserung, zu oberflächlicher Atrophie des Irisgewebes an der entsprechenden Stelle, was bei einem so empfindlichen Organ leicht erklärlich ist. Das Irisgewebe kann eine derartige leichte Veränderung auch nach einfachen Entzündungsformen eingehen. Eine das Irisstroma durcbsetzende Narbe habe ich nach stattgehabter Resorption dieser Nodi in keinem Falle beobachten können. Diese vollständige Resorptionsfähigkeit der Irisknoten, welche ohne den geringsten nachtheiligen Einfluss auf den empfindlichen Mutterboden statthaben kann, weist dahin, dass das pathologische Product mehr die oberfächlichen Schichten der Iris zu seiner Matrix hat.

Es zeigt die Art der Involution, dass diese Producte vom Anfunge ihres Entstehens bis zu ihrem vollständigen Sehwunde stets in einem festen Aggregationszustande verharren. Auf Grund meiner Beobachtungen muss ich der Ansicht entgegentreten, als würden diese mit dem Cumulationsnamen "Gumma" gekennzeichneten Gebilde in Abscesse sich umwandeln, oder auf dem Wege des eitrigen Zerfalles zu Grunde gehen. Wir finden schon bei Mackenzie*) die Ansicht vertreten, dass diese Gummata (Tuberkeln) Pusteln, manchmal Abscesse bilden. Derselben Anschauung waren Ricord, Robert Melchior und Nyman, welche

*) 1. c. 56, p. 18.

7. Graefe's Archip fitr Ophthalnalogie, X $x$ VII. 2. 
angeben, dass die Umwandlung der Iritisknoten in Abscesse etwas ganz Gewöhnliches sei, und dass als Resultat des eitrigen Zerfalles dann Hypopyum erscheine. Derselben Ansicht sind v. Graef $\left.e^{*}\right)$, Mooren**), Mauthner, Stellwag***). In seinem neueren Werke scheint jedoch Stellwag $\dagger$ ) dieser Anschaung nicht mehr in dieser Allgemeinheit zu huldigen und hebt hervor, dass diese „Gummata" sich häufig rasch resorbiren. Bei keinem der von mir beobachteten Fälle sogenannter Tritis gummosa komte ioh eine Umwandlung dieser Nodi in Abscesse sehen, viel weniger einen eitrigen Zerfall derselben, oder geradezu, wie Stellwag behauptet, einen dadurch bedingten Substanzverlust auf denselben. Ist Hypopyon bei lritis syphilitica überhaupt selten, so ist es bei der mit Knotenbildung einhergehenden Form nicht häufiger. Und wenn auch Hypopyon vorhanden war, so war es mir auch bei der genauesten Beobachtung nie möglich, auch nur eine Spur einer stattgehabten Veränderung in dem Aggregationszustande der Knoten oder einen Substanzverlust an der Oberfläche derselben zu entdecken, was jedenfalls geschehen sein müsste, falls diese Producte als die Quelle des producirten Eiters angesehen werden könnten. Ich muss daher annehmen, dass die Quelle eines Hypopyon auch bei dieser Iritisform nur da zu suchen sei, wo dieselbe bei einfach nicht luetischen und bei einfach specifischen Iritiden ist. Da meine eigenen Beobachtungen nicht zahlreich genug sind, um sie als massgebend hinstellen zu wollen, sei es mir gestattet, mich auf Beobachter wie Arlth), Zehendertit), Schmidt*f) and

*) l. c. 27, p. 205.

**) 1. c. 581867, p. 140.

***) l. c. 85, p. 293 u. 294.

†) 1. c. 86, p. 288 .

十) 1. e. 2, p. 67 .

t+十) 1. c. 87. p. 253 .

*f) l. c. 89, p. 274 . 
Wecker*) zu stützen, welche ebenfalls nie eitrigen Zerfall derIrisknoten gesehen haben. Wecker hebt auch hervor, dass die gelbliche Farbe, welche diese Nodi in einem gewissen Entwicklungszustande zeigen, nicht auf Exsudatgehalt zurückzuführen sei, da zahlreiche gemachte Einschnitte zeigten, dass eine solide Masse vorhanden, diese Irisknoten einen festen Aggregationszustand besassen. Mooren**) selbst giebt zu, dass in dem von ihm operirten und mitgetheilten Falle, wo das mit der Pincette gefasste Gumma ganz zerfiel, dies nicht in dem etwaigen eitrigen Inhalt, sondern in der weichen Structur dieser Producte begründet war, welche beim Fassen oft in eine gallertartige Masse zerfallen können. Die anatomisohen Thatsachen sowohl soweit dies überhaupt möglich - als namentlich die klinischen Ergebnisse, kennzeichnen daher den als Iritis gummosa gekannten Krankheitsprocess als eine Localmanifestation der Frühphase der Syphilis, das knotenförmige Product selbst dem entsprechend als eine syphilitischePapel.

Zwei Thatsachen muss ich noch anführen, die in gewisser Beziehung zu den mitgetheilten Beobachtungen stehen. In neuerer Zeit ist zuerst von H. Schmidt***) eines eigenthümlichen bei Iritis vorkommenden Exsudates Erwähnung geschehen, welches er als gallertartiges Exsudat bezeichnete. Bald darauf erfolgten mehrfache Beobachtungen gallertigen Exsudates, so von Gunning $\dagger$ ), Gruening †), Hock $+\dagger$ ), Heimann*†), Drognat-Lan-

\footnotetext{
*) 1. c. 102, p. 360 .

**) 1. c. 581867, p. 48 .

* 1. c, 90, p. 94.

t) 1. c. 32, p. 7 .

t+) 1. c. 33, p. 166.

tt十) 1. c. 41.

*t) 1. c, 40 .
} 
dré(), Kipp**), Laqueur***), Keyser†), Klotz†i, Schmidt+it), Schmalenbach*t), Schliephacke*ti), . Sehroder*ift). Es wurde das gallertartige Exsudat sowohl als das, als Vorstadium desselben angegebene schwammige (Gruening) bei Iritiden ganz verschiedenen Ursprunges beobachtet, bei idiopathischen sowohl als traumatisehen und anderweitigen. Ja nicht einmal die Mehrzahl der mitgetheilten Fälle kamen bei syphilitischen Iritiden vor. Es besteht also kein tieferer Connex zwischen dieser Art des Exsudates and der syphilitischen Iritis. Hierorts berucksichtige ich diese Exsudatform nur insofern, als dieselbe such in einzelnen Fällen von Iritiden mit Knotenbildung beobachtet wurde (Gruening, von Schröder, Kipp) Letzterer hat das Exsudat von den Irisknoten abgeleitet, indem er sagt: „In Folge genauer und häufiger Beobachtung bin ich ganz sicher, dass das Exsudat von dem Gummaknoten herrührt, denn dort kam es zuerst zum Vorschein und von da breitete es sich nach allen Richtungen aus; das Gumma war offenbar eine damit zusammenhängende Masse." $\dagger^{*}$ ) Bei dem Falle von Gruening war der früber erbsengrosse Tumor nach erfolgter Resorption des sich sehr rasch entwickelnden Exsudates bis anf Hanfkorngrosse reducirt gewesen. v. Schröder neigt auch dahin, den Irisknoten für den Ausgangspunkt des Exsudates zu lalten. Diese Angaben nun fühten dahin, dass die Irisknoten nicht nur als Quelle und Ausgangspunkt des gallert-

*) 1. c. 24 .

**) 1. c. 46, p. 191.

****) 1. c. 52, p. 329 .

f) l. c. 48, p. 451 .

t广) l. c. 49, p. 161 .

t+t) 1. c. 93, p. 315 .

*t) l. c. 92 ,

$*++$ ) 1. c. 94 , p. 293.

*t+f) 1. c. 97, p. $37-43$.

t*) l. e. 46, p. 192 
artigen Exsudates angenommen wurden, sondern man hielt sogar das Exsudat für eine Art Detritusmasse des Irisknotens. Es würde daher das Ganze als eine Art der Involution der Irisknoten betrachtet werden können.

Unter den von mir mitgetheilten Fällen von Iritis mit Knotenbildung waren zwei Fälle mit gelatinösem Exsudate. Ausser diesen hatte ich Gelegenheit, noch anderweitige einschlägige Beobachtungen zu machen. Bei zwei solchen Fällen, von welchen der eine in der Tabelle enthalten (l'abelle II. F. 4), konnte ich genau beobachten, dass die Entwicklung des Exsudates ganz unabhängig von der des Trisknotens vor sich ging. Das Exsudat hatte trotz seiner Mächtigkeit das Gumma derart freigelassen, dass zwischen beiden nicht die geringste Verbindung wahrgenommen werden konnte. Es lehrte mich die genaue Beobachtung dieser Fälle, dass Exsudat and Irisknoten ein von einander ganz unabhängiges Dasein führen. Beide wiesen einen solch; von einander ganz unabhängigen Verlauf nach, dass auch nicht die geringste Veränderung an dem Irisknoten wahrnehmbar war, weder beim Entstehen noeh im ganzen Verhalten und der erfolgenden Resorption des Exsudates, welche mit letzteren Veränderungen in ein Abhängigkeitsverhältniss hätten gebracht werden können. Von einer Volumsveränderung des Irisknotens zur Zeit als das Exsudat verschwand, kounte ich nie die geringste Spur erkennen. Fs würde übrigens, falls diese meine Beobachtung auch nicht vorläge, kaum begreiflich sein, dass dieses für gewobnlich massige Exsudat von dem Irisknoten geliefert werden könnte, wenigstens nach dem Volumsverhältnisse beider könnte dies als gar nicht möglich betrachtet werden, Ich glaube daher auch die von Gruening angegebene Thatsache einfach auf den Umstand zurückführen zu dürfen, dass während der Zeitdauer, wo das gallertartige Exsudat seiner Resorption entgegen ging, der Irisknoten sich gleichfalls selbstständig in seiner Grösse rückbildete. 
Die bestimmte Entscheidung dieser Frage muss jedenfalls yon der erst zu erfolgenden Bestimmung des Wesens dieser gallertartigen Exsudate abhängig gemacht werden. Manche betrachten die gallertartige Masse in der Kammer als Exsudationsproduct, Andere wieder als Lymphextravasat (Heimann, Schliephaoke); auf die meisten Beobachter machte es den Eindruck eines Productes, hervorgerufen durch einen Coagulationsprocess. Ich selbst möchte mich vorläufig letzterer Ansicht anschliessen, namentlich in Berücksichtigung dessen was ich gesehen habe. So konnte ich in einem Falle, wo das mächtige Exsudat mehr als die Hälfte der Vorderkammer erfüllte, innerhalb 36 Stunden das Entstehen und die vollständige Resorption desselben beobachten. Eine solch eminente Raschheit leitet unwillkürlich den Gedanken auf einen Gerinnungsprozess hin, als dessen Resultat sich dann das gallertartige Exsudat einstellt. $\mathrm{Ob}$ der Gerinnungsprozess die Folge einer durch die Entzündung gesetzten fibrinreichen Flüssigkeit allein ist, die die Bedingung zur Gerinnung in sich trägt (fibrinogene Substanz A. Schmidt) oder dieselbe erst eine nachträgliche Gerinnung des Kammerwassers bedinge, oder beide Umstände vereint obwalten, wird sich wohl schwer entscheiden lassen. Fs könnte übrigens das gallertartige Exsudat der Hauptsache nach aus dem geronnenen Kammerwasser allein bestehen, bedingt durch eine eigenthümliche krankhafte Veränderung der die Kammer auskleidenden Membranen - nach Art der Coagulirung des Blutes bei krankhafter Intima. Jedenfalls könnte eine derartige Ursache bei den verschiedensten Iritiden eintreten. Sicher ist, dass das Exsudat kein Detritusproduct der Irisknoten sein kann.

Das Zweite, dessen Erwähnung ich nicht unterlassen kann, bezieht sich auf eine von Knapp*) gemachte Mit-

*) 1. c. 44, p. 216. 
theilung betreffs einer zweiten Form von Irisknoten. "Diese zweite Form tritt ouf als umschriebene röthliche Ansehwellung auf der Vorderfäche der Iris (Papel), welche in ihrem Wachsthume sich immer mehr über die Oberfläche erhebt, und als eine einfache oder zerklüftete condylomatöse Excrescenz in die vordere Kammer hineinragt." Ich vermeine durch wörtliche Wiedergabe der Knapp 'schen Mittheilung am Besten nachgewiesen zu haben, dass dieselbe mit meinen Angaben absolut nichts gemein hat, abgesehen davon, dass ich diese von Knapp geradezu als die häufgere der Knotenformen angegebene, selbst ebensuwenig wie Mauthner*) bisher zu beobachten die Gelegenheit hatte.

Mein Bestreben in dieser Arbeit war bisher die Stellung zu präcifiren, welche die Iritis im Systeme der Syphilis einnimmt und den Beweis zu liefern, dass die einfach syphilitische sowie die sogenannte gummöse Iritis eine luetische Ersoheinung der Frühphase der Syphilis sei. Es erübrigt nur noch die Beantwortung der auch ron Virchow*) aufgestellten, aber von ihm unentschieden gelassenen Frage: "giebt es eine Iritis der Tertiärperiode?", eine wahre Iritis gummosa? - Die Entscheidung wird sich am Besten aus einer Beobachtung ergeben, welche ich in der Klinik von Arlt machte.

W..., Marie, 42 Jahre alt, giebt an vor 11 Jahren abortirt zu haben; vor 8 Jahren hatte sie ein Fussleiden, das ein halbes Jabr andanerte.

Vor 6 Jahren bekam sie Geschwüre im Gesichte, am Halse und an der rechten Oberextremität. Vor 5 Jahren abermaliger Abortus. Die obengenannten Geschwüre zeigten fast gar keinen Heilungstrieb, so dass sie durch Jahre andanerten. Die Patientin hatte im Ganzen 7 Kinder, die alle im Alter von 2-4 Jahren starben. Vor 4 Wochen bekam sie zum ersten

*) l. c. 59, p. 277.

***) l. c. 109 , p. 307 . 
Wale Schmerzen im linken Auge nebst dem Gefühle von Spannung. Seit 14 Tagen bemerkte sie eine Geschwulst am linken Auge. Das Sehvermögen soll bis vor einigen Tagen links ebenso gut als rechts gewesen sein. Einen Ausschlag hat sie nie gehabt. Status praes. Mässig genährtes Individuum. An der rechten Tibia eine central geschrumpfte Narbe, unter welcher ein grosser Knochendefect $z u$ fühlen ist. Ausserdem zahlreiche alte central-deprimirte Hautnarben am rechten Olecranon, eine eingezogene, einem Knochendefekte entsprechende Narbe am linken Olecranon, Hautnarben am Halse und im Gesichte. Der Nasenrücken eingesunken, ausgedehnte alte Knochendefecte im Stirnbeine. Die Sprache nässelnd. An den verschiedensten Stellen des Körpers vergrösserte, harte, nicht schmerzhafte Lymphdrüsen. Syphilis im gummösen Stadium. R. A. normal. L. A. Die Bindehaut der Lider mässig injicirt, starke Ciliarinjection. Nächst dem oberen inneren Rande der Cornea sitzt eine grane weiche Geschwulst von eirca $7 \mathrm{~mm}$ Durchmesser. Dieselbe ragt halbkugelig hervor und ist von verdünnter Conjunctiva überzogen. Die Cornea ist matt, von feinen trüben Flecken durchsetzt, und zeigt nach unten vom Centrum ein etwa hirsekorngrosses gelbliches Infiltrat, das in den tieferen Schichten der Hornhaut liegt. Vordere Kammer tiefer als normal, am Boden derselben ein $1 \mathrm{~mm}$ hohes Hypopyon. Iris verfärbt. Die Pupille durch vorspringende Synechien unregelmässig, $3-4 \mathrm{~mm}$ weit, unbeweglich. Die Pupille ist etwas nach innen oben, entsprechend der Geschwulst verzogen. Die Geschwulst selbst scheint vom Ciliarkörper auszugehen. Tn. Finger in $0,5 \mathrm{~m}$. Es wurde die Diagnose auf Gumma corporis ciliaris gestellt. Th. Inunkt. à 2,5 gr, 20 an Zahl, dann Jodkalium, unter welcher Behandlung das Gumma rasch sich verkleinerte, die Gegend, in welcher dasselbe sass, immer flacher wurde und das Sehvermögen sich besserte. Nach zweimonatlicher Behandlung war die Stelle des Gumma vollkommen flach, nur grauweisslich durehschimmernd. $\mathrm{s} \frac{6}{24}$. Ophthalmoscopischer Befund normal.

Diese Beobachtung liefert nun mit Sicherheit den Nachweis für das Vorhandensein eines wahren, dem gummösen Stadium anģehörenden Productes im Ciliarkörper. Es gibt eine wahe Cyklitis gummosa. Dieser Fall, 
- der anch noch ein hohes Interesse bietet, da es trotz eines Gumma corporis ciliaris nicht zur Atrophie des Bulbus kam - beantwortet daher die obige Frage, was den Ciliarkörper anbelangt, mit Sicherbeit bejahend. Alt*) theilt überdies den pathologisch-anatomischen Befund von einem wegen Iridocyklitis specifica enucleirten Auge mit. Das Product, ein vereinzeltes Gumma im Ciliarkörper, besass in hohem Grade all diejenigen Charaktere, welche von Virchors gummösen Producten zugesprochen wurden. Ohne auf den detaillirten Befund des Näheren einzugehen, will ich nur erwähnen, dass hierbei das Heterogene der Elemente ganz deutlich in den Vordergrund tritt. Es lronnte ein bedeutender, vom Centrum der Geschwulst ausgehender fettiger Zerfall der Elemente constatirt werden. Das Gumma war im Ciliarkörper eingebettet, dessen Muskelfasern auseinandergedrängt wurden. Höchst charakteristisch war das Verhaiten der Blutgefässe. Trotz des höchst gefässreichen Mutterbodens waren in der Neubildung gar keine Gefässe nachweisbar, und in der Umgebung des Tumors selbst waren die Gefässe auf ein Minimum beschränkt. Es entsprieht dieses anatomische Verhalten in Allem ganz genau demjenigen, welches ich als für Gummaproducte charakteristisch berits erwähnt habe.

Es fragt sich nun, wie verhält sich die Tris in dieser Beziehung? Die Iris ist nicht nur ihrer Innervation und Ernährungsquelle nach, sondern auch histologisch ein mit dem Ciliarkörper einheitliches Ganze. Es ist daher nur naturgemäss, dass die Iris den Mutterboden fur all diejenigen Krankheitsprocesse abgeben kann, welche im Ciliarkörper sich localisiren. Da diese Thatsache bei den versehiedenartigsten Erkrankungsformen des vorderen Theiles des Uvealtractes de facto beobachtet wird, so muss im speciellen Falle die für den Ciliarkörper nachgewiesene

*) 1. c. 4, p. 16 und 1. c. 5, p. 117 . 
Erkrankungsform auch für die Iris angenommen werden. Diese muss daher den Mutterboden abgeben können für tertiär-luetische Producte und Processe. Es giebt in der That ein wahres Gumma iridis und in diesem Sinne eine Iritis der Tertiärperiode, eine wahre Iritis gummosa.

Deshalb habe ich die Moglichkeit hingestellt, dass es auch in der Tertiärperiode der Syphilis eine von der Allgemeinerkrankung unmittelbar abhängige, eine wahre specifische Iritis giebt. Ein solches wahres Gumma iridis dürfte der bereits erwähnte Fall von v. Hippel gewesen sein. Ich wüsste mir ferner die von Wecker, Stellwag und Mooren angeführten Beobachtungen nicht besser zu erklären, als dass ich sie auf wahre Gummata der Iris zurückführe. So behauptet v. Wecker*), dass die Irisknoten die käsige Metamorphose eingehen können und solche ständig eine Narbe in der Iris hinterlassen. Stellwag**) beschreibt als eine Art der Involution mancher Irisknoten, „dass dieselben auch ständig werden können, indem sie veröden. Die kleineren schrumpfen dann in hartliche, mehr oder weniger pigmentirte Knötchen zusammen, welche oft viel Fett und Kalk führen." Sind auch diese Angaben vielleicht nicht genau genug, um ein bestimmtes Urtheil zuzulassen, so geben sie doch ein ziemlich klares Bild von der regressiven fettig-käsigen Metamorphose, welche eine der charakteristischsten Eigenthîmlichkeiten gummöser Producte ist. Jedenfalls steht dieselbe im vollen Gegensatze zu jener vollständigen Resorptionsfähigkeit, welche die von nir als Papeln bezeichneten Irisknoten eingehen. Mooren ${ }^{* *}$ ) führt an, dass manche der Irisknoten in einzelnen Fällen von

*) 1. c. 108, p. 248.

**) 1. c. 85 II, B., p. 298 und 1. e. 86, p. 218.

***) 1. c. 58.1873, p. 84 u. 49. 
„exquisit harter Structur" seien, im Gegensatze zu der gewöhnlich mehr gallertartigen Beschaffenheit der Irisknoten. "Ich wage nicht $z \mathrm{u}$ entscheiden" - sagt er „ob die Neubildungen an sich different, oder aber ob ihre ungewơhnliche Festigkeit nur ein Beweis für die Tiefe der Allgemeinerkrankung ist." Nun kann es, dem Mitgetheilten gemäss, wohl keinem erheblichen Zweifel unterliegen, dass Uooren dasselbe sah, was Stellwag beschrieben hatte, wie auch, dass diese wirklich wesentlich anderweitiger Natur als die anderen gallertartigen weichen Producte. Und insofern war auch die Vermuthning Mooren's ganz richtig, dass diese Producte als wahre Gummata der Iris Ausdruck der erheblichen Schwere und Tiefe des Allgemeinleidens seien.

Dass diese wahren Gummata der Iris, entsprechend anderen gummösen Producten, entweder einer fettig-käsigen Metamorphose unterliegen können, oder eventruell auch eitrig zerfallen können, so dass sie in dem Gewebe des Mutterbodens tiefe Narben setzen, bedarf wohl keiner weiteren Erörterung.

Die jedenfalls ausserordentliche Seltenheit von wahren Gummata der Iris kann nicht berechtigen, die Existenz und das Vorkommen derselben zu leugnen. Berücksichtigt man einerseits die Seltenheit der Fälle überbaupt, wo die Syphilis in ihrer Tertiärperiode als Localität ihrer Manifestationen dic Iris sich auserwählt, anderseits den Umstand, dass die Iris zur Localisation gummöser Producto einen höchst ungünstigen Boden abgiebt, so wird die ausserordentliche Rarität wahrer gummöser Iritis leicht erklärlich. Virchow*) selbst sagt, dass man nicht übersehen darf, dass die Iris ein so zartes Organ ist, dass sie wenig geeignet erscheint, jene solerosirenden abcapselnden

*) 1. c. 109 , p. 306 . 
Schichten zu bilden, innerhalb deren sich die käsigen Massen abgeschlossen erhalten.

Ich war bestrebt nachzuweisen, dass mit dem Cumulationsnamen "Gumma" der Tris höchst differente Krankheitsprocesse and Producte zusammengefasst werden. Es ist dies ein Versuch Formen zu scheiden, die bisher fälschlich zusammengefasst worden waren, die aber in Bezug auf ihr klinisches Verhalten, ihr Entstehen, ihren Verlanf und ihre Involution, ja sogar auch anatomisch, so wenig einander gleichen, dass es höchst gewagt wäre, dieselben auf ein und dieselbe klinisch-anatomische Basis zurückzuführen. Weit entfernt daher, das Vorkommen wahrer Gummata der Iris in Abrede zu stellen, handelte es sich mir in dieser Arbeit mehr darum, das zum wesentlichen Nachtheile klarer Begriffe ungebührlich erweiterte Gebiet der Iritis gummosa einzuschränken. Zweck dieser Arbeit war daher auch, einerseits auf eine bisher nicht hinlänglich oder gar nicht gewürdigte Iritisform, der Iritis papulosa, anderseits ihr gegenüber auf die zweite der Tertiärperiode der Syphilis angehörende Iritisform, auf das wahre Gumma iridis, auf die Iritis gummosa aufmerksam zu machen.

Die strenge Scheidung zwischen Iritis papulosa und Iritis gummosa hat aber auch einen praktischen Werth. Ich erwähnte bereits die Thatsache, dass in dem gummösen Stadium der Syphilis Jodpräparate dieselbe Rolle spielen, wie Merkur in der Frühphase der Syphilis. Dieser Umstand wird demn auch bei der Iritis syphilitica und ihren verschiedenartigen Formen nicht ausser Acht gelassen werden dürfen.

Resumire ich nun die aus dieser Arbeit sich ergebenden Thatsachen, so sind es zunächst folgende:

Die Syphilis sehliesst das zeitliohe Vorhandensein einer idiopathischen Iritis nicht ans.

Es giebt eine Iritis specifica, die als solche in unmittelbarem Abhängigkeitsverhältnisse zur constitutionellen $\mathrm{Sy}$ - 
philis steht. Die Iritis specifica ist eine locale Manifestation des condylomatösen Stadiums der Syphilis, daher eine secundär-luetische Erscheinung. Die einfache Iritis ist daher nur dann eine im wahren Sinne des Wortes specifisch-luetische, wenn das condylomatöse Stadium der Syphilis objectiv nachweisbar ist.

Die der Spätperiode der Syphilis sich zugesellenden Iritiden stehen für gewohnlich zur Allgemeinerkrankung nicht mehr in derselben unmittelbaren Abhängigkeit, sind daher nicht wabre specifische Iritiden, sondern für gewöhnlich nur Iritiden in einem syphilitisehen Individuum, das bereits der Cachexie unterliegt. Ausgenommen müssen diejenigen Fälle werden, wo Producte in der Iris zur Entwicklung kommen, die als solche dem gummösen Stadium der Syphilis zukommen (wahres Gumma), und ihre Specifität eben dadurch documentiren.

Unter dem Namen Gumma der Iris und Iritis gummosa werden zwei verschiedenartige Inetisehe Producte und Krankheitsprocesse zusammengefasst, die von einander streng zu scheiden sind.

Der eine und zwar der hänfigste für gewöhnlich mit dem Namen Iritis gummosa bezeichnete Krankheitsprocess ist ebenso wie die einfach specifische Iritis eine Localmanifestation des condylomatösen Stadiums der Syphilis, und das als Gumma bezeichnete knotenförmige Neugebilde ein secundär-luetisches Product, eine syphilitische Papel der Iris; der Krankheitsprocess selbst eine Iritis papulosa.

(Es giebt ein wahres Gumma des Ciliarkörpers, eine dem gummösen Stadium der Syphilis angehörende Cyklitis gummosa).

Es giebt im Gegensatze zur syphilitischen Papel der Iris ein wahres Gumma iridis, eine Iritis, welche der Tertiarrperiode der Syphilis (gummöses Stadium) angehört, eine Iritis gummosa. 


\section{Benutgte Literatur.}

1. v. Ammon, De Iritide. Commentatio etc. Lipsiae 1838.

2. v. Arlt, Krankheiten des Auges. Prag 1863.

3. Alexander, Ueber syphilitische Augenerkr. Corresp. d. ärztl. Ver. im Rheinl. 1874. No. 13.

4. Alt, Beiträge zur patholog. Anat. d. Auges. Knapp, Arch. VI., Bd. 1. A. p. 1-21. 1877.

5. Alt, Compendium d. norm. n, path. Histologie d. Auges. Wiesbaden 1880.

6. Auspitz, DieLehrevom syphilitisehen Contagium. Wien 1866.

7. Beer, Lehre von den Augenkrankheiten. Wien 1813.

8. Barbar, Ueber einige seltenere syph. Erkrank. d. Auges. Diss. Zürich 1873.

9. Bull, Charles, Observations on some syphilitic lesions of the Eye with cases. Americ. Journ. of med. Sciences. Vol. 69,1875 , p. $412-426$.

10. Boeck, Undersögelser angaande Syphilis, fortsaetelse af Recherches sur la Syphilis, appuyées de tableaux de statistique. Christiania 1875.

11. Barensprung, Die hereditare Syphilis. Berlin 1864.

12. Bärensprung, Mittheilungen aus d. Abth. u. Kl. f. syph. Kr., Annal. d. Charité-Krank. IV., VI., VII., IX. Bd.

13. Bäumler, Syphilis. Ziemssen, Handb. d. spec. Path. u. Ther. III. Bd.

14. Biesiadecky, Beiträge z. path. Anatomie. Sitzb, d. Acad. d. Wiss. Wien 1867, 21. Jhrg.

15. Birch-Hirsehfeld, Lelrb. d. patholog. Anatomie. Leipzig 1877.

16. Carmichael, Observat, on the effic. of Turpnt. in the Vener. and oth. inflam. of the Eye. Dublin 1829.

17. Cullerier, Iritis syphilitique. Gan. des Hop. T. VT. Juin No. 27, 1844. 
18. Coccius u. Wilhelmi, Die Heilanstalt f. arme Augenkr. in Leipzig 1870.

19. Déval, Des affect. vénériennes de l'oeil. Gaz. méd. de Paris 1848.

20. Desmarres, Traité des maladies des yeux. Paris 1859 .

21. Droste. Ueber Iritis. Deutsche Klinik 1867, No. 6.

22. Delafield, General syph. inflam. of the Eye. Transact. of the Amer. ophth. Soc. T. VIII 1871.

23. Dreschfeld, The Lond. Lancet. 1875, 16. Jan.

24. Drognat-Landré, De l'iritis syphilitique, Annal. d'ocul. T. LXXIII, 1875, p. 250-264.

25. Fournier, Des affect. oculaires d'orig. syphil. Journ. d'Ophth. T. I, p. 495-503, 543-560.

26. Förster, Beziehg. d. Allgleiden. u. Org.-Erkr. zu Veränd. u. Krkh. d. Auges. Handb. v. Graefe-Saemisch. VII. B. 5 Th. Cap. XIII.

27. v. Graefe, Vortrag über Iritis syph. Deutsche Klinik 1858. No. 21.

28. v. Graefe, Zur Casuistik d. Geschwülste, A. f. O. VII. B. 2 A., p. 35.

29. v. Graefe, Ein Fall von Sarcoma iridis, mitg. v. Hirsehberg. A. f. 0. XIV. B., 3. A., p. 285.

30. Graefe, Alfr. u. Colberg. Iritis gummosa. A. f. 0 . VIII. B., 1. A., p. 288.

31. Galezowszky, Traité des maladies des yeux. Paris 1872.

32. Gunning, Ueber gallertartige Ausschwitzg. in die vord. Kammer. Klin. Monatsb. f. Aughl. X. B. p. 7. 1872.

33. Gruening, Ueber schwammiges Exsudat in d. vord. Augenkammer. Knapp, Arch. III. B. 1. A. p. 166. 1873.

34. Hewson, Pract. observ. on the his., nat. and treatm. of th. vener. diseas. of the Eye. Lond. 1836.

35. Hasner v. Artha, Entwurf einer anat. Begründg. d. Augenkrkhtn. Prag 1847.

36. Hutchinson, Ueber syph. Augenkrkhtn. Ophth. Hosp. Reports. ete. Juni 1859.

37. Helbert, Ueber syphilitisehe Iritis. Dentsche Klinik, 1850. No. 10.

38. v. Hippel u. Neumann, Fall v. gummöser Neubldg. in sämmtl. Häut. d. Auges. A. f. O. XIII. B. 1. A. p. 65-74. 1867. 
39. Hirschberg und Steinheim, Ueber Granalationsgeschwulst d. Tris. Knapp's Áreh. I. B. 2.A. p.144-152. 1870.

40. Heimann, Weitere Beitrg. z. Kenntn. d. vasomot. a. secret.Neur. d.Auges. Knapp's Arch. V.B. 2.A. p. 308. 1876.

41. Hock, Die syphilitisch.Augenerkx. Wiener Klinil IT. Jhrg. 3. и. 4. Heft, 1876.

42. Haab, Die Tuberknlose d. Anges. A. f. 0. XXII. B. 2. A.

43. Krieger, Ueber einigo Formen $\nabla$. Iritis. Dentsche Klinik 1851. No. 6.

44. Knapp, Die intraoculären Geschwülste. 1872.

45. Knapp u. Robertson, Sarcom d. Iris. Knapp's Arch. III. B. 2. A. p. 131.

46. Kipp, Syphilit. Tritis mit gelatinösem Exsudate. Knapp's Arch. III. B. 1. A. p. 191, 1873.

47. Kipp, Teber einen Fall von primärem Irissarcom. Knapp's Areh. V. B. 1. A. p. 177.

48. Keyser, Clinic. contrib. 1. Iritis with. gelatin. exsud. entr. the ant. chambre. Philad. med. and. surg. Rep. march. 7. 1877. p. 451.

49. Klotz, Iritis rheumat. à forme anormale. Bordeaux méd. 1874. p. 161.

50. Law rence, On the rener. diseases of the Eye. Lond. 1830.

51. Loring, E. G., Syphil. Gumma in the ciliary body. Transact. of the Amer. Ophth. Soc. 1874, p. 174-178.

52. Laqueur, Ref. in Nagel's Jahresb. f. Ophth. 1874, p. 329.

53. Leber, Beiträge z. Aetiol. innerl. Augenentz. Vrtrg. Ber. der XII. Vers. d. ophth. Ges. Heidelberg 1879.

54. Lebert, Handbueh d. pract. Medicin. 1859.

55. Lancereaux, E., Traité théor. et prt. de la syphilis. 2. edit. Paris 1874.

56. Mackenzie, Traité prat. des malad. de l'oeil. trd. p. Warlomont et Testelin. Paris $\mathbf{1 8 5 7}$.

57. Manz, Ref. in Nagel's Jahresb. f. Ophth. 1871. p. 222.

58. Mooren, Ophthalmiatrische Beobachtungen. Berlin 1867 und 1873.

59. Mauthner, Krankh. d. Anges, in Zeissl's Lehrb. d. Syphilis, II. B. p. 261.

60. Michaelis, Compend. ₹. der Lehre der Syphilis. Wien 1859.

61. Michaelis, Der Contagienstreit in der Lehre t. d. Syphilis. Virchow's Arch. B, 24 1. Heft p. 57. 
62. Nymann, Quelques reflex. sur les erupt. syph. et sur leur valeur dans les ophth. syph. Annal. d'Oeulist. T. XIX. p. 274.1848.

63. Nettleship, Ed., Clinic. notes on iritis espee. as to the relat. frequency of syph. etc. Brit. med. Journ. 1876. No. 11. p. 617.

64. Neumann, Diagnostik u. Ther. d. Hautsyph. Wiener Klinik. II. B. 1876. 2. Heft.

65. Pilz, Lehrbuch d. Augenkrankht. 1858.

66. Perls, Zur Kenntniss der Iristuberculose, mit Nachtrag von Jacobson. A. f. 0. B. XIX. 1. A., p. 247.

67. Panas, Leçons sur les malad. inflam. des membr. int. de l'oeil. Paris 1878.

68. Ruete, Lehrbuch der Ophthalmol. Braunschweig 1854.

69. Ricord, Traité de la maladie vénér. 1852.

70. Ricord, Lettres sur la Syphilis. 1856 und 1863. $2^{\text {e }}$ et $3^{e}$ edit.

71. Rieord, Leçons sur le chanere, publ. p. Alfr. Fournier. Paris 1858 u. $1860.2^{\mathrm{e}}$ edit.

72. Ricord, Traité prat. des malad. vénér., recherches crit. et exp. sur l'inoc. Paris 1838.

73. Ricord, Traité compl. des malad. vén. Clinique iconog. de l'hôpit. des vẻnér. Paris 1852.

74. Rie ord, De l'iritis syphilitique. Annal. d'oculist. T.XXXVI.

75. Robrin et Nysten, Diction. Art. Cystoblast.

76. Robin, Des tumeurs gum. 1859.

77. Robert Melchior, Mém. sur l'intis syph. etc. Revue méd. chir. T. X., auch Ann. d'ocul. 1851.

78. Robert Melchior, Nouveau traité des maladies véneriennes. Paris 1861.

79. Reder, A, Pathol. u. Ther. d. vener. Krankh. Wien 1863.

80. Reder, Die Perioden der Syphilis. Arch. f. Dermt. und Syph. III. Bd. 1871.

81. Rindfleisch, Lehrb. der path. Gewebel. 1878.

82. Rollet, Traité des malad, véner. Paris 1872.

83. Sichel, De l'iritis syphilitique. Journ. des connaiss. méd. déc. 1840, p. 65 et suiv.; janv. 1841.

84. Sichel, Iconographie ophthalm. Paris 1854.

85. Stellwag v. Carion, Die Ophthalmologie ₹. naturwissenschaftlichen Standpunkte. Erlangen 1855.

จ. Graefe's Archiv für Ophthalmologie. XXVII. a. 
86. Stellwagr v. Carion, Lehrbuch d. prakt. Augenheilkunde. 4. Aufl. Wien 1870.

87. Seitz-Zehender, Handbuch der gesammten Augenheilkunde. Eirlangen 1869.

88. Schweigger, C., Handbuch der spec. Augenheilkunde. Berlin 1871.

89. Schmidt, H., Beiträge z. Kenntniss der Iritis syphilitica. Berl. kl. Wochenschr. 1872, X. Bd., Nr. 23 u. 24.

90. Schmidt, H., Eigenthümlich geformte Exsudate bei Iritis. Klin. Monatsbl. f. Augenheilk. IX. Bd. 1871. p. 94.

91. Sehnütgen, Das Granulom. Diss. Bonn 1872.

92. Schmalenbach, J., Zur Casuistik geformter Exsudate bei Iritis. Diss. Greifswald 1874.

93. Schmidt, Linsenähnliches Exsudat bei Iritis. Klin. Monatsbl. f. Augenheilk. 1875. XIII. Bd., p. 315.

94. Schliephacke, H., Zur Kenntniss der vasomot. und secret. Neurosen des Auges. Knapp, Arch., V. B. 1876. 2. Abth. p. 293.

95. Schnabel, Die Begleit- und Folgekrankh. der Tritis. Knapp, Archiv. V. B. 1. Aufl.

96. Seggel, Teber Irido-Chorioiditis gummosa. Knapp, Arehiv. 1880. IX. B. 4. Abth. p. 454.

97. v. Schröder, Beitrag zur Kenntniss der Iritis syphilitica. Diss. Dorpat 1880.

98. Schubert, Ueber syphilitische Augenkrankh. Berlin 1881 .

99. Simon, Syphilis. Virchow's Handb. d. spec. Path. u. Ther. II. B. 1853.

100. Sigmund, Syphilis u. vener. Gesehwulstformon, in PithaBillroth's Handbuch.

101. v. Wecker, Die Erkrankungen d. Uvealtract, u. Glaskrp. Handb. V. Graefe-Saemisch. TV. B., 2. Th.

102. v. Wecker, Traité thér. et prat. des maladies des yeux. Paris 1863.

103. v. Wecker-Masselon, Thérapent. ocul. Paris 1878.

104. Woinow, Fall von Gumma corpor. cilar. Compt. rend. de la Soc. Russe de Mose. 1873.

105. Velpeau, Dict. en 30 vol, Art. Iritis u. Gaz. des Hôp. 1845, No. $55-71$.

106. Vidal, Traité des malad. vénériennes. Paris 1855.

107. Verneuil, Mém. de la Soc. de Biol. 1854. 
108. Virchow, Vortrag über Syphilis. Deatsche Klinik 1858. No. 21.

109. Virchow, Ueber die Natur der constit. syph. Affect. Arch. f. path. Anat. XV. B. 1858, 3. u. 4. Heft.

110. Virchow, Die krankhaften Geschwülste. Berlin 1863.

111. Wagner, Das Syphilom. Arch. f. Heilkunde. IV. B. 1863.

112. Zeissl, Ueber Verhärtung der periph. Lymphdrüsen. Wochenbl. d. Ges. d. Aerzte in Wien 1857. No. 52.

113. Zeissl, Vortrag über die Vulnerabitität Syphilit. Wochenbl. d. Ges. d. Aerzt. in Wien 1865. No. 11.

114. Zeiss 1, Lehrb. d. Syphilis u. d. verw. ortl. vener. Krankheiten. Wien, 3 Aufl. 1875.

115. Zeissl, Die dureh Syphilis hervorger. Erkr. d. Augenlider. Wien, Allg. med. Ztg. 1877. No. 28, 29, 35 bis 37. 


\section{Tabelle I.}

Iritis syphilitica ohne Knoten.

\begin{tabular}{|c|c|c|c|}
\hline 㿣 & $\frac{d}{d}$ & 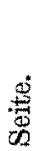 & $\begin{array}{l}\text { Zeit } \\
\text { zwischen } \\
\text { Primär- } \\
\text { affect und } \\
\text { Angener- } \\
\text { krankung. }\end{array}$ \\
\hline
\end{tabular}

Gleichzeitig vorhandene anderweitige luetische Erscheinungen.

Männer.

\begin{tabular}{|c|c|c|c|c|}
\hline 1 & 25 & $\mathrm{R}, *)$ & $8 \mathrm{M}+\mathrm{T}$ & $\begin{array}{l}\text { An den Weichen und am Rücken ein- } \\
\text { zelne theils im Abblassen, theils in } \\
\text { Sehuppung begriffene, in kleinen } \\
\text { Gruppen stehende Papeln. Recidi- } \\
\text { virende Form. }\end{array}$ \\
\hline 2 & 39 & L.*** & $5 \mathrm{~W} . \dagger \dagger$ & - \\
\hline 3 & 20 & $\mathrm{R}$ & $4 \mathrm{M}$ & - \\
\hline 4 & 23 & B. $* * * 4$ & $7 \mathrm{M}$ & $\begin{array}{l}\text { Algemeine Drüsensehwellung, Condylo- } \\
\text { mata lata ad anum, zerfallende Papeln } \\
\text { an den Tonsillen. }\end{array}$ \\
\hline 5 & 28 & R. & $2 \mathrm{~J} . \mathrm{t+}$ & $\begin{array}{l}\text { Scleradenitis universalis multiplex. Pa- } \\
\text { pulae ad scrotum; Plaques muqueuses } \\
\text { an der Lippensehleimhaut und Zunge. }\end{array}$ \\
\hline 6) & 33 & L. & $4 / 2 \mathrm{M}$ & - \\
\hline 7 & 32 & L. & $3_{2}^{1} \mathrm{M}$. & - \\
\hline 8 & 40 & $\mathrm{R}$. & $1 / 1 / 2 \mathrm{~J}$. & $\begin{array}{l}\text { Exanthema papulosum am ganzen } \\
\text { Stamme. }\end{array}$ \\
\hline
\end{tabular}

*) $\mathrm{R}=$ rechtes Auge.

**) $\mathrm{L}=$ linkes Auge.

****) $\mathrm{B}=$ beide Angen.

f) $\mathrm{M}=$ Monat.

t) $\mathrm{W}=$ Woche.

十七t) $\mathrm{J}=\mathrm{Jahr}$. 


\begin{tabular}{|c|c|c|c|c|}
\hline 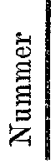 & 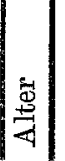 & 覃 & $\begin{array}{l}\text { Zeit } \\
\text { zwischen } \\
\text { Primär } \\
\text { affect und } \\
\text { Augener- } \\
\text { lkrankung }\end{array}$ & $\begin{array}{l}\text { Gleichzeitig vorhandene anderweitige } \\
\text { luetische Erscheinungen. }\end{array}$ \\
\hline 9 & $30 \mid$ & B. & $10 \mathrm{M}$. & $\begin{array}{l}\text { Zahlreiche kleinere abgeblasste Flecke } \\
\text { aw Stamme, zerstreut stehende papu- } \\
\text { löse Efflorescenzen an der Brust und } \\
\text { am Rücken. }\end{array}$ \\
\hline 10 & 33 & I. & $6 \mathrm{~W}$. & $\begin{array}{l}\text { Sclerose im sulc. retrogland, frisches } \\
\text { maculo - papulöses Exanthem am } \\
\text { Stamme; zerfallende Papeln ad anum } \\
\text { und am Scrotum. }\end{array}$ \\
\hline 11 & $|28|$ & L. & $6 \mathrm{M}$. & 一 \\
\hline 12 & 53 & L. & - & Psoriasis palmaris. \\
\hline 13 & 21 & R. & $31 / \mathrm{M}$. & $\begin{array}{l}\text { An der Corona glandis und am innern } \\
\text { Blatte des Präputiums Sclerose. Am } \\
\text { ganzen Stamme ein theils maculöses, } \\
\text { theils papulöses Syphilid, von denen } \\
\text { einzelne bereits in Desquamation be- } \\
\text { griffen. Plaques muqueuses an der } \\
\text { Lippenschleimhaut. }\end{array}$ \\
\hline 14 & $46 \mid$ & L. & $5 \mathrm{M}$. & $\begin{array}{l}\text { Am Stamme ein maculo-papulöses Sy- } \\
\text { philid. }\end{array}$ \\
\hline 15 & $22 \mid$ & $\mathrm{R}$. & $?$ & $\begin{array}{l}\text { An der Schleimhaut der Lippen zerfal- } \\
\text { lende Papeln, ebenso an den Ton- } \\
\text { sillen. }\end{array}$ \\
\hline 16 & 49 & L. & $5 \mathrm{~J}$. & $\begin{array}{l}\text { Erst seit kurzer Zeit bestehende Alo- } \\
\text { pecia areolata; beiderseits Psoriasis } \\
\text { palmaris. Plaques muqueuses an der } \\
\text { Lippenschleimhaut. }\end{array}$ \\
\hline 17 & 44 & R. & $3 / 2 \mathrm{M}$ & - \\
\hline 18 & 30 & R. & $1_{1 / 2}^{1 / 2}$ & $\begin{array}{l}\text { Scleradenitis universalis multiplex. Re- } \\
\text { cidivirendes papulöses Exanthem an } \\
\text { der Brust und an den Weichen; con- } \\
\text { dylomata lata ad anum. }\end{array}$ \\
\hline
\end{tabular}




\begin{tabular}{|c|c|c|c|c|}
\hline 旁 & $\frac{9}{\frac{9}{4}}$ & 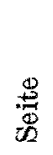 & $\begin{array}{l}\text { Zeit } \\
\text { zwisehen } \\
\text { Primâtir- } \\
\text { affect tud } \\
\text { Augener- } \\
\text { luankung }\end{array}$ & $\begin{array}{l}\text { Gleichzeitig vorhandene anderweitige } \\
\text { lnetische Erseheinungen. }\end{array}$ \\
\hline 19 & 29 & B. & $10 \mathrm{~J}$ & $\begin{array}{l}\text { An der Klinik des Prof. Sigmund } \\
\text { wurde die Diagnose (mit Wahrschein- } \\
\text { lichkeit) anf Syphilis im gummösen } \\
\text { Stadium gestellt. }\end{array}$ \\
\hline 20 & 34 & I. & $9 \mathrm{~J}$. & $\begin{array}{l}\text { Flache Geschwüre an der Schleimhaut } \\
\text { der Yundlippen, plaques an der } \\
\text { Zunge, Geschwüre an den Tonsillen. }\end{array}$ \\
\hline
\end{tabular}

\section{Weiber.}

\begin{tabular}{|c|c|c|c|c|}
\hline & 32 & B. & - & $\begin{array}{l}\text { Am Stamme ein frisches maculo-papu- } \\
\text { loses Exanthem. }\end{array}$ \\
\hline 22 & 26 & R. & - & $\begin{array}{l}\text { Ausgebreitetes maculo-papulöses Syphi- } \\
\text { lid am Stamme; zerfallende Papeln am } \\
\text { obern und untern Lide des r. Auges, } \\
\text { ähnliehe am Tarsus. }\end{array}$ \\
\hline 23 & 46 & R. & - & Am Körper ein maculöses Syphilid. \\
\hline 24 & 27 & $\mathrm{R}$. & $41 / 2 \mathrm{M}$. & - \\
\hline 25 & 23 & $\mathrm{R}$. & - & $\begin{array}{l}\text { Spuren eines im Abblassen und in } \\
\text { Desquamation begriffenen Exanthems. } \\
\text { Papeln an den grossen Labien. }\end{array}$ \\
\hline & 34 & B. & $4 \mathrm{M}$. & - \\
\hline 27 & 36 & R. & $5_{2} \mathrm{M}$. & $\begin{array}{l}\text { Patientin wurde gleich, nur mit dem } \\
\text { Primäraffect behaftet, mit Sublimat- } \\
\text { pepton behandelt (Prof. Bamberger), } \\
\text { es trat kein Exanthem auf, auch jetzt } \\
\text { ausser allg. Drüsenschwellung keine } \\
\text { weitere Erscheinung der Lues nach- } \\
\text { weisbar. }\end{array}$ \\
\hline 28 & 47 & L. & $3 \mathrm{ML}$. & $\ldots$ \\
\hline 29 & 24 & R. & 2常 $\mathrm{M}$. & $\begin{array}{l}\text { Am Stamme ein desquamirendes maculo- } \\
\text { papulöses Syphilid. }\end{array}$ \\
\hline
\end{tabular}




\begin{tabular}{|c|c|c|c|c|}
\hline | & $\frac{5}{4}$ & $\frac{8}{6}$ & $\begin{array}{c}\text { Zeit } \\
\text { zwischen } \\
\text { Primär. } \\
\text { affeet und } \\
\text { Augener- } \\
\text { krankrung }\end{array}$ & $\begin{array}{l}\text { Gleichzeitig vorhandene anderweitige } \\
\text { luetische Erscheinungen }\end{array}$ \\
\hline 30 & 20 & R. & $12 \% / 2 \mathrm{M}$ & $\begin{array}{l}\text { An den kleinen Labien Reste der bereits } \\
\text { fast vollständig involvirten Sclerose. } \\
\text { Condylomata Iata ad anum und in } \\
\text { den Ano-labial-Falten. }\end{array}$ \\
\hline 31 & 23 & B. & $\begin{array}{l}\text { leugnet } \\
\text { Lues. }\end{array}$ & $\begin{array}{l}\text { Adenitis universalis multiplex. An der } \\
\text { Stirne und am Rücken ganz charak- } \\
\text { teristische papulöse Efflorescenzen, } \\
\text { Rachenkatarrh. }\end{array}$ \\
\hline 32 & 24 & B. & $4 \mathrm{M}$ & $\begin{array}{l}\text { Maculöses Syphilid. Papulae ad anum } \\
\text { et ad lab. maj. }\end{array}$ \\
\hline 33 & 18 & R. & $7 \mathrm{M}$. & $\begin{array}{l}\text { Am ganzen Körper ein klein papulöses } \\
\text { Syphilid. }\end{array}$ \\
\hline 34 & 51 & B. & $\begin{array}{l}\text { leugnet } \\
\text { Lues. }\end{array}$ & $\begin{array}{l}\text { Lymphadenitis universalis. Der ganze } \\
\text { Körper mit einem frischen maculo- } \\
\text { papulosem Syphilide bedeckt. }\end{array}$ \\
\hline 35 & 40 & B. & - & $\begin{array}{l}\text { Am Stamme ein maculo-papulöses } \\
\text { Syphilid. Plaques an der Mund- } \\
\text { schleimhaut. Psoriasis palmaris. }\end{array}$ \\
\hline 36 & 21 & L. & $7 \mathrm{M}$. & $\begin{array}{l}\text { Am Stamme ein im Abblassen begrif- } \\
\text { fenes desquamirendes Syphilid. }\end{array}$ \\
\hline 37 & $23 \mid$ & B. & $5 / 2 \mathrm{M}$ & $\begin{array}{l}\text { Desquamirendes papulöses Syphilid am } \\
\text { Stamme. Scleradenitis universalis. } \\
\text { Am freien Rande des r. Oberlides } \\
\text { eine bis zur innern Kante reichende } \\
\text { papulöse Efflorescenz. }\end{array}$ \\
\hline 38 & 35 & L. & $\begin{array}{l}\text { Leugnet } \\
\text { Lues }\end{array}$ & $\begin{array}{l}\text { Papulae luxuriantes confluentes ad lab. } \\
\text { maj. regressal in lab. min.; an der } \\
\text { Haut linsengrosse, stellenweise sich } \\
\text { schuppende, hellbraune Pigmentflecke } \\
\text { (syph. Exanthem in Involution be- } \\
\text { griffen). }\end{array}$ \\
\hline
\end{tabular}




\begin{tabular}{|c|c|c|c|c|}
\hline 兽 & 焉 & 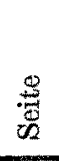 & $\begin{array}{c}\text { Zeit } \\
\text { zwisenen } \\
\text { Primär- } \\
\text { affect und } \\
\text { Augener- } \\
\text { krankung }\end{array}$ & $\begin{array}{l}\text { Gleichzeitig vorhandene anderweitige } \\
\text { luetische Erscheinungen. }\end{array}$ \\
\hline 39 & 40 & L. & $10 \mathrm{M}$ & Papulöses Syphilid am Stamme. \\
\hline 40 & 29 & B. & - & $\begin{array}{l}\text { Lymphadenitis univers. Am Stamme } \\
\text { ein grosspapulöses Syphilid, zerfal- } \\
\text { lende Papeln an der rechten Hälfte } \\
\text { des palatum molle. }\end{array}$ \\
\hline 41 & 31 & I. & $8 \mathrm{M}$. & $\begin{array}{l}\text { An den Weichen dem Anschein nach } \\
\text { recidivirende papulöse Efflorescenzen. }\end{array}$ \\
\hline 42 & 62 & $\mathrm{R}$. & - & Am Stamme ein kleinpapulöses Syphilid. \\
\hline 43 & 36 & $\mathrm{R}$. & - & $\begin{array}{l}\text { Am ganzen Körper ein dicht stehendes, } \\
\text { theilweise confluirendes maculo-papu- } \\
\text { löses Syphilid. }\end{array}$ \\
\hline 44 & 37 & $\mathrm{R}$. & - & $\begin{array}{l}\text { Am ganzen Stamme ein im Abblassen } \\
\text { begriffenes maculöses Exanthem. }\end{array}$ \\
\hline 45 & 43 & P. & - & $\begin{array}{l}\text { Am Stamme ein desquamirendes macu- } \\
\text { löses Exanthem. Psoriasis palmaris. }\end{array}$ \\
\hline 46 & 42 & B. & $6 \mathrm{M}$. & - \\
\hline 47 & $|43|$ & B. & $4 \mathrm{M}$. & - \\
\hline 48 & 63 & B. & $2 / 2 \mathrm{M}$ & $\begin{array}{l}\text { Am Stamme und an der Stirn ein klein- } \\
\text { papuloses Syphilid. Scleradenitis uni- } \\
\text { versalis; zerfallende Papeln an den } \\
\text { Tonsillen. }\end{array}$ \\
\hline 49 & $\mid 38$ & B. & - & $\begin{array}{l}\text { Am Stamme ein kleinpapuloses Sy- } \\
\text { philid. }\end{array}$ \\
\hline
\end{tabular}




\section{Tabelle II.}

Iritis syphilitica mit Knoten.

(Iritis papulosa.)

\begin{tabular}{|c|c|c|c|c|c|}
\hline $\begin{array}{l}\text { 总 } \\
\text { 煦 }\end{array}$ & 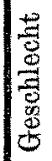 & $\frac{5}{4}$ & 总 & $\begin{array}{l}\text { Zeit } \\
\text { zwischen } \\
\text { Primär. } \\
\text { affect und } \\
\text { Augener- } \\
\text { krankung }\end{array}$ & $\begin{array}{l}\text { Gleichzeitig vorhandene anderweitige } \\
\text { luetische Erscheinungen. }\end{array}$ \\
\hline 1. & $M$. & 29 & R. & $5 \mathrm{M}$. & $\begin{array}{l}\text { Plaques muqueuses an der Lippen- } \\
\text { und Mundschleimhant, Condylo- } \\
\text { mata ad anum. }\end{array}$ \\
\hline 2. & M. & 28 & $\mathrm{R}$. & $4 \mathrm{M}$. & $\begin{array}{l}\text { Am Stamme ein im Abblassen be- } \\
\text { griffenes desquamirendes Syphilid. }\end{array}$ \\
\hline 3. & M. & 31 & L. & $1 \mathrm{~J}$. & $\begin{array}{l}\text { Am Präputium eine sich hart an- } \\
\text { fühlendeNarbe, allgemeine Drüsen- } \\
\text { schwellung; condylomata lata ad } \\
\text { scrotum, zerfallende Papeln an den } \\
\text { Tonsillen. Alopecia areolata. }\end{array}$ \\
\hline 4. & M. & 20 & R. & $8 \mathrm{M}$. & $\begin{array}{l}\text { Am Frenulum eine Narbe. Sclera- } \\
\text { denitis universalis; am Stamme } \\
\text { zahlreiche braunrothe pigmentirte } \\
\text { linsengrosse Flecke. Plaques mu- } \\
\text { queuses an der Rachenschleimhant. } \\
\text { (Gelatinöses Exsudat.) }\end{array}$ \\
\hline 5. & $\mathrm{M}$. & 29 & I. & 3/2 M. & Am Stamme ein maculöses Syphilid. \\
\hline 6. & W. & 21 & R. & - & $\begin{array}{l}\text { Am Stamme ein papulöses Syphilid } \\
\text { (L. A. Iritis syphilitica [ohne } \\
\text { Knoten]). }\end{array}$ \\
\hline 7. & W. & 41 & L. & $2 \mathrm{Mr}$. & $\begin{array}{l}\text { Maculöses Syphilid. Condylomata ad } \\
\text { anum. *) }\end{array}$ \\
\hline
\end{tabular}

*) Die Augenerkrankung trat gleichzeitig mit dem luetischen Exantheme auf. 


\begin{tabular}{|c|c|c|c|c|c|}
\hline 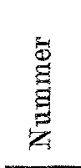 & $\begin{array}{c}1 \\
0 \\
0 \\
\\
0 \\
0 \\
0 \\
0\end{array}$ & 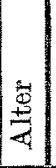 & 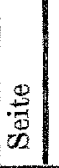 & $\begin{array}{c}\text { Zeit } \\
\text { Zwischen } \\
\text { Primär- } \\
\text { affect und } \\
\text { Augener. } \\
\text { lrankung }\end{array}$ & $\begin{array}{c}\text { Gleichzeitig vorhandene anderweitige } \\
\text { luetische Erscheinungen. }\end{array}$ \\
\hline 8. & $W$. & 37 & L. & 7有 M. & $\begin{array}{l}\text { Am stamme ein im Abblassen be- } \\
\text { griffenes maculo-papulöses Ex- } \\
\text { anthem, - theilweise in Des- } \\
\text { quamation begriffen. }\end{array}$ \\
\hline 9. & W. & 25 & R. & - & $\begin{array}{l}\text { Am Stamme sowohl als an der Stirne } \\
\text { zahlreiche dichtgestellte kupfer- } \\
\text { rothe Flecke. Erythema maculo- } \\
\text { papulosum.*) }\end{array}$ \\
\hline 10. & W. & 32 & R. & $2 \mathrm{M}$. & $\begin{array}{l}\text { Sclerose in der Fossa navicularis. } \\
\text { Am Stame ein papuloses Syphilid. }\end{array}$ \\
\hline 11. & W. & 38 & R. & 坆 J。 & $\begin{array}{l}\text { Am Stamme einzelne papulöse Efflo- } \\
\text { rescenzen - recidivirende Form } \\
\text { - ; condylomata lata ad anum.**) }\end{array}$ \\
\hline 12 & W. & 30 & $\mathrm{R}$. & $4 \mathrm{M}$ & $\begin{array}{l}\text { Am Stamme ein in Desquamation } \\
\text { begriffenes maculöses Syphilid.***) }\end{array}$ \\
\hline
\end{tabular}
Knoten).

*) Gelatinöses Exsudat L. R. A. Iritis syphilitica (ohne

**) Iritis syphilitica (ohne Knoten) L. A.

***) Iritis syphilitica (ohne Knoten) L. A.

t) Ambulatorischer Fall. L. A. Tritis syphilitica (ohne Knoten). 